\title{
Revisiting food-sourced vitamins for consumer diet and health needs: A perspective review from vitamin classification, metabolic functions, absorption, utilization, to balancing nutritional requirements.
}

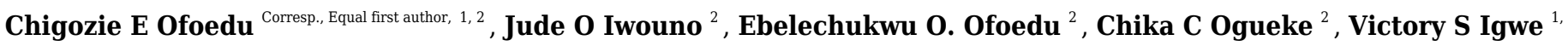
${ }^{2}$, Ijeoma M Agunwah ${ }^{2}$, Arinze F Ofoedum ${ }^{2}$, James S Chacha ${ }^{1,3}$, Onyinye P Muobike ${ }^{2}$, Adedoyin O Agunbiade ${ }^{1,4}$, Njideka E Njoku ${ }^{2}$, Angela A Nwakaudu ${ }^{2}$, Nkiru E Odimegwu ${ }^{2}$, Onyekachi E Ndukauba ${ }^{2}$, Chukwuka U Ogbonna ${ }^{5}$, Joncer Naibaho ${ }^{\text {Corresp., } 6}$, Maciej Korus ${ }^{6}$, Charles Odilichukwu R Okpala ${ }^{\text {Equal first author, } 6}$

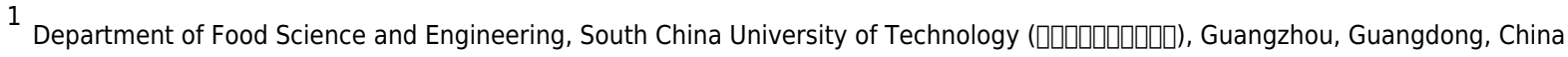

2 Department of Food Science and Technology, Federal University of Technology, Owerri, Imo State, Nigeria

3 Department of Food Technology, Nutrition, and Consumer Sciences, Sokoine University of Agriculture, Chuo Kikuu, Morogoro, Tanzania

4 Department of Food Science, University of Ibadan, Ibadan, Nigeria

5 Department of Biochemistry, Federal University of Agriculture, Abeokuta, Ogun, Nigeria

6 Faculty of Biotechnology and Food Science, Wroclaw University of Environmental and Life Sciences, Wroclaw, Poland

Corresponding Authors: Chigozie E Ofoedu, Joncer Naibaho

Email address: chigozie.ofoedu@futo.edu.ng, joncer.naibaho@upwr.edu.pl

The significant attention gained by food-sourced vitamins has provided insights into numerous current researches, for instance, the potential reversal of epigenetic age using a diet and lifestyle intervention, the balance between food and dietary supplements in the general population, the role of diet and food intake in age-related macular degeneration, and the association of dietary supplement use, nutrient intake and mortality among adults. As relevant literature about food-sourced vitamin increases, continuous synthesis is warranted. To supplement existing information, this perspective review discussed foodsourced vitamins for consumer diet and health needs, scoping from vitamin absorption, metabolic functions, utilization, to balancing nutritional requirements. Relevant literatures were identified through a search of databases like Google Scholar, Web of Science, Interscience Online Library,ScienceDirect, and PubMed. We demonstrated that vitamins whether from plant- and animal-based sources areprerequisites for the metabolic functions of the human body. The fat- and water-soluble classification of vitamins remains consistent with their respective absorption and dissolution potentials, underpinned by numerous physiological functions. Vitamins, largely absorbed in the small intestine, have their bioavailability dependent on the food composition, its associated interactions, as well as alignment with their metabolic functions, which involves antioxidants, coenzymes, electron acceptor/donor, and hormones. Moreover, vitamin deficiencies, in every form, pose a serious threat to human health. Vitamin toxicities remain rare, but can still occur mainly Peer] reviewing PDF | (2021:03:59124:1:1:NEW 28 Jun 2021) 
from supplementation, although it appears much less in water-soluble vitamins of which some excesses get readily removed by the human body, different from the fat-soluble ones that are stored in tissues and organs. Besides discussions of absorption, transport, and cellular uptake of vitamins, this perspective review also included approaches to meeting vitamin requirements and therapeutic strategies against micronutrient deficiency and COVID-19. We have also attempted on how to strike the balance between foodsourced vitamins and dietary supplements. 
1 Revised for acceptance: PeerJ

2 Revisiting food-sourced vitamins for consumer diet and health

3 needs: A perspective review from vitamin classification, metabolic

4 functions, absorption, utilization, to balancing nutritional

5 requirements

6 Chigozie E. Ofoedu ${ }^{1,2^{*} \dagger}$, Jude O. Iwouno ${ }^{1}$, Ebelechukwu O. Ofoedu ${ }^{1}$, Chika C. Ogueke ${ }^{1}$, Victory

7 S. Igwe ${ }^{2}$, Ijeoma M. Agunwah ${ }^{1}$, Arinze F. Ofoedum ${ }^{1}$, James S. Chacha ${ }^{2,3}$, Onyinye P. Muobike ${ }^{1}$,

8 Adedoyin O. Agunbiade ${ }^{2,4}$, Njideka E. Njoku ${ }^{1}$, Angela A. Nwakaudu ${ }^{1}$, Nkiru E. Odimegwu ${ }^{1}$,

9 Onyekachi E. Ndukauba ${ }^{1}$, Chukwuka U. Ogbonna ${ }^{5}$, Joncer Naibaho ${ }^{6 *}$, Maciej Korus ${ }^{6}$, and

10 Charles Odilichukwu R. Okpala ${ }^{6 \dagger}$

$11{ }^{1}$ Department of Food Science and Technology, School of Engineering and Engineering

12 Technology, Federal University of Technology, Owerri, Imo State, Nigeria.

13 2Department of Food Science and Engineering, South China University of Technology,

14 Guangzhou, Guangdong, China.

15 '3epartment of Food Technology, Nutrition, and Consumer Sciences, Sokoine University of

16 Agriculture, Chuo Kikuu, Morogoro, Tanzania.

$17{ }^{4}$ Department of Food Science, University of Ibadan, Ibadan, Nigeria.

18 Department of Biochemistry, Federal University of Agriculture Abeokuta, Ogun State, Nigeria.

$19{ }^{6}$ Faculty of Biotechnology and Food Science, Wroclaw University of Environmental and Life

20 Sciences, Wroclaw, Poland.

21 *Corresponding Authors: chigozie.ofoedu@futo.edu.ng (CE Ofoedu);

22 joncer.naibaho@upwr.edu.pl (J Naibaho)

23

†Equal first author: This author contributed equally to this review and should be considered cofirst author. charlesokpala@gmail.com (COR Okpala) 


\section{ABSTRACT}

45 The significant attention gained by food-sourced vitamins has provided insights into numerous 46 current researches, for instance, the potential reversal of epigenetic age using a diet and lifestyle intervention, the balance between food and dietary supplements in the general population, the role of diet and food intake in age-related macular degeneration, and the association of dietary supplement use, nutrient intake and mortality among adults. As relevant literature about foodsourced vitamin increases, continuous synthesis is warranted. To supplement existing information, this perspective review discussed food-sourced vitamins for consumer diet and health needs, scoping from vitamin absorption, metabolic functions, utilization, to balancing nutritional requirements. Relevant literatures were identified through a search of databases like Google Scholar, Web of Science, Interscience Online Library, ScienceDirect, and PubMed. We demonstrated that vitamins whether from plant- and animal-based sources are prerequisites for the metabolic functions of the human body. The fat- and water-soluble classification of vitamins remains consistent with their respective absorption and dissolution potentials, underpinned by numerous physiological functions. Vitamins, largely absorbed in the small intestine, have their bioavailability dependent on the food composition, its associated interactions, as well as alignment with their metabolic functions, which involves antioxidants, coenzymes, electron acceptor/donor, and hormones. Moreover, vitamin deficiencies, in every form, pose a serious threat to human health. Vitamin toxicities remain rare, but can still occur mainly from supplementation, although it appears much less in water-soluble vitamins of which some excesses get readily removed by the human body, different from the fat-soluble ones that are stored in tissues and organs. Besides discussions of absorption, transport, and cellular uptake of vitamins, this perspective review also included approaches to meeting vitamin requirements and therapeutic strategies against micronutrient deficiency and COVID-19. We have also attempted on how to strike the balance between food-sourced vitamins and dietary supplements.

Keywords: food-sourced; animal sources; plant sources; vitamin absorption; vitamin transport; micronutrient; physiological function

\section{INTRODUCTION}

Nutrients are a prerequisite to human life, and among them include vitamins that play several important physiological roles (Combs, 2008). Being low molecular weight organic compounds distinct from macronutrients such as carbohydrates, proteins, and fats, vitamins are micronutrients the human body requires for optimal cell development/growth, as well as countless metabolic functions/processes (Combs, 2008; Goncalves et al., 2015). Besides assisting 
77 in the synthesis of nervous system chemicals, blood vessel formation, hormones, and genetic 78 materials, it is widely understood that vitamins can, when combined with proteins, serve as a 79 80 catalyst to generate metabolically active enzymes necessary for life processes (Cooper, 2000; Bhagavan \& Ha, 2015). Though the human body needs vitamins to work properly, most vitamins appear not synthesised within the body, at least not in sufficient amounts to meet our daily needs (SAL, 2017; Kumanyika \& Oria, 2017), and therefore must be obtained from the diet. Compared to other classes of such nutrients like carbohydrate, protein, and fat, the breakdown (catabolism) of vitamins neither provides significant energy nor structural functions to the body. Instead, very small quantities (micrograms or milligrams per day) are required to perform the highly specific and unique functions of health maintenance and metabolic integrity (Bender, 2003). This, therefore, distinguishes vitamins from fatty acids and amino acids, which are nutrients required in larger amounts, and also from inorganic minerals and trace elements. Briefly, vitamins are distinguishably grouped into fat-soluble vitamins (A, D, E, and K) and water-soluble vitamins (B-complex and C) based on their absorption potential in either fat (non-polar medium) or water (polar medium), in addition to the region of their physiological activity (Zhao et al., 2019). The magnitude of their dissolution is influenced by some intrinsic and extrinsic factors which would be discussed later in this perspective review. Generally, the fat-soluble are well-known as lipophilic (oil-loving) organic compounds while the water-soluble vitamins are regarded as the hydrophilic (water-loving) organic compounds.

However, besides being a disparate group, vitamins nutritionally form a cohesive group of organic compounds that are neither chemically identical nor able to provide similar metabolic functions (Bender, 2003). Vitamins as micronutrients have assumed outstanding public health importance. As a result, multiple studies have been conducted to provide a clearer understanding of their physiological function and associated health implications of the deficiency of these micronutrients in diets. For instance, as vitamin A deficiency has been implicated to be the leading cause of blindness and high risk of death from common illnesses such as diarrhoea in children, it has been classified by the World Health Organization as a public health problem affecting children in South Asia and sub-Saharan Africa (UNICEF, 2019). Unlike macronutrient (carbohydrate and protein) deficiency, the health implications of micronutrient deficiencies are not always visible, hence the term hidden hunger. It is well recognized that malnutrition in every aspect poses a great threat to public health, as the World Health Organization estimates the 
108 number of people with micronutrient deficiency in the world to be over two billion (UNICEF,

109 2019). The prevalence of the most common vitamin deficiency globally is briefly shown in Table

110 1. Given this, understanding the significance of establishing the magnitude of (public health)

111 severity of this micronutrient's malnutrition and providing adequate control and preventive

112 measures is very crucial (FAO/WHO, 2004). No single food source contains all the vitamins and

113 inadequate or suboptimal consumption of vitamins results in deficiencies. This implies that

114 different foods are needed to meet the vitamin requirement of the body (SAL, 2017).

115 Importantly, the occurrence of micronutrient (vitamin) malnutrition in an individual, could be an

116 indication of vitamin deficiency, attributable not only to poor consumption of vitamin-rich diets

117 but also due to factors influencing vitamin absorption. Besides inadequate ingestion of vitamin-

118 rich foods, some of the factors that can cause vitamin deficiency as a result of impairment of

119 intestinal vitamin absorption are genetic disorders in transport molecules, intestinal disease,

120 interactions with certain drugs and some food components, and excessive alcohol consumption

121 (Said, 2004; Iqbal \& Hussain, 2009; Bowen, 2019).

122 Understanding the key mechanisms involved in vitamin absorption has been among the

123 key challenges confronting researchers in this food-related discipline. For instance, some

124 researchers of previous studies provided evidence suggesting that some fat-soluble vitamins were

125 absorbed by passive diffusion while other vitamins of the same class were absorbed through

126 carrier-dependent proteins (Goncalves et al., 2015). Interestingly, recent studies have shown that

127 the mechanism of vitamin absorption, as well as transportation of absorbed vitamins, are

128 somewhat compounded than earlier stated, as their mode of absorption appears to be

129 concentration-dependent. For example, a high concentration of these fat-soluble vitamins is

130 absorbed through passive diffusion while protein-mediated transport occurs at dietary doses

131 (Reboul \& Borel, 2011). On the other hand, for water-soluble ones, vitamin absorption does

132 occur via diffusion.

133 Briefly, the absorption of vitamins begins with chewing of ingested food, where enzymes

134 start to play their role from the mouth, together with continued churning and mixing with other

135 chemical constituents in the stomach. The churned food makes contact with the small intestine,

136 which is the nutrient absorption center in the body. Further, the water-soluble vitamins diffuse

137 through the intestinal walls into the bloodstream while the fat-soluble vitamins are emulsified

138 and packaged in lipid-rich mixed micelles containing fatty acids, bile salt, and phospholipids. 
139 Subsequently, fat-soluble vitamins would be moved through the brush-like projections (villi) and

140 absorbed into the lymphatic circulation where they are transported to tissues, target cells, or

141 organs (liver) (El-Kattan \& Varma, 2012; Khammissa et al., 2018). As relevant literature

142 regarding food-sourced vitamins increases by the day, there is a need for continuous synthesis to

143 update existing information. To supplement existing information, this perspective review

144 discussed food-sourced vitamins for consumer diet and health needs, scoping from vitamin

145 absorption, metabolic functions, utilization, to balancing nutritional requirements. For emphasis,

146 this perspective review has been constructed as follows: a) classification of vitamins; b) sources

147 of vitamins; c) metabolic functions of vitamins; d) absorption of vitamins; e) vitamin transport; f)

148 characteristic interactions associated with food-sourced vitamins g) vitamin deficiencies and

149 toxicities; h) approaches to meeting vitamin requirements; i) vitamins as a therapeutic tool

150 against micronutrient deficiency and Covid-19; as well as j) establishing a balance between

151 food-sourced vitamins and dietary supplements. This work intends to disseminate an abridged

152 version of existing information about key vitamin research studies and the same time, revisit

153 the state-of-the-art. In considering its exceptional public health importance, the physiological

154 functions, and associated health implications of respective deficiencies, the continuous literature

155 synthesis on the severity of the diverse vitamin deficiency around the globe makes this review

156 very fitting. Following this, the current perspective review is essential, not only for the general

157 public, but also for nutritionists, dietitians, food scientists, public health, and health-related

158 specialists, together with their respective organizations, to understand better the mechanisms of

159 vitamin transport and utilization, including the rationale for the impairment of vitamin

160 absorption.

\section{SURVEY METHODOLOGY}

162 The formulating of research questions was the very step in actualising this perspective

163 review. We made effort to ensure the research questions were directly relevant to the intended

164 objective, and at the same time, considered the intended/target audience. After this, a search

165 strategy was developed by consulting and collating published papers and their references from

166 selected scientific databases, including Google Scholar, ISI Web of Science, ResearchGate,

167 Interscience Online Library, ScienceDirect, Semantic Scholar, and PubMed/Medlin. Each

168 database was searched using keywords and search terms such as vitamin absorption, mechanism 
169 of vitamin absorption, utilization of vitamin, transportation of vitamin, and cellular uptake of the

170 vitamin. Further, the inclusion and exclusion criteria were established, which through the help of

171 search strategy helped to determine the research articles that are appropriate, relevant, and

172 specific to the objective of this perspective review.

173 Primary research studies reporting the fundamental aspects of vitamin in nutrition and

174 health were included. Specifically, studies were selected if they evaluated vitamin and their

175 associated body functions, vitamin and food component interaction, as well as vitamin

176 requirement in human nutrition. Articles reporting food-sourced vitamins especially from plant

177 and animal origin were equally included because we considered them relevant for this review.

178 Excluded studies were those that evaluated and reported other sources of vitamins such as

179 vitamins exclusively produced from microorganisms, vitamins as nutritional supplements,

180 vitamin-like compounds, and vitamin mimic. It is important to reiterate here that all the

181 publications in languages other than English were also excluded. Additionally, we applied

182 discretion to strike a balance between the year of publication and the relevance of the

183 information to the objective of this review. Next, the information gathered from the selected

184 literature/studies were analysed and all information deemed relevant were incorporated, which

185 helped to expatiate the discourse of this conducted perspective review.

\section{DISCUSSION OF LITERATURE SYNTHESIS}

\section{Classifications of Vitamins}

188 In human nutrition, the traditional and widely accepted means of classifying the well-

189 known thirteen vitamins have been based on their solubility, which includes: fat-soluble

190 (hydrophobic) and water-soluble (hydrophilic) vitamins. The flow diagram showing the

191 classifications of vitamins is shown in figure 1. This classification of vitamins is basically

192 dependent on their absorption potential either in fat or water (Bhagavan \& Ha, 2015), together

193 with where they act in the body (Delaney \& Barke, 2017). The degree of vitamin dissolution in

194 fat or water varies and is influenced by intrinsic and extrinsic factors. The fat-soluble vitamins

195 are oily hydrophobic (lipophilic) organic compounds, usually not excreted out of the body, but

196 rather stored in the body (liver), which include vitamins A, D, E, and K. In contrast, the water-

197 soluble vitamins are hydrophilic (lipophobic) organic compounds not stored in the body and

198 easily excreted through urine. Water-soluble vitamins are, therefore, required daily in small

199 amounts, which include vitamin C (ascorbic acid) and the members of the vitamin B group, 
200 namely thiamine (vitamin B1), riboflavin (vitamin B2), niacin (vitamin B3), pantothenic acid

201 (vitamin B5), pyridoxine (vitamin B6), biotin (vitamin B7), folate (vitamin B9), and cobalamin

202 (vitamin B12) (Ball, 2004). Further, it is well-known that almost all vitamins are considered

203 essential for their role in physiological processes and must be obtained from food, but some

204 vitamins that can be synthesized endogenously in the body are not technically considered

205 "essential" and they include vitamins D, B7, and K. The chemical structure of all the vitamins

206 are shown in figure 2.

207 a) Fat-soluble vitamin group

208 i) Vitamin $A$ :

209 Generically, vitamin A is a group of essential fat-soluble micronutrients of identical

210 compounds known as retinoid (Delaney \& Barke, 2017). Vitamin A is categorised in dietary

211 form as either provitamin A or previtamin A. The provitamin A is exclusively synthesised by

212 plants and present in the diet in foods of plant origin. Provitamin A is mainly composed of

213 carotenoids consisting of $\beta$-cryptoxanthin, $\alpha$-carotene, and $\beta$-carotene (Ross \& Harrison, 2014)

214 Carotenoids are pigments produced by plants that give plants their range of colours, such as red,

215 yellow, and orange. The body cells can utilize and convert (transform) carotenoids ( $\beta$ -

216 cryptoxanthin, $\alpha$-carotene, and $\beta$-carotene) to vitamin A (Newman, 2017), given the $\beta$-carotene

217 conversion rate to vitamin A as 12:1 and 24:1 for $\beta$-cryptoxanthin (Scott, 1994; Goncalves et al.,

218 2015).

219 On the other hand, previtamin A, in the form of vitamin A, is synthesized by animals and

220 derived from diets in foods of animal origin. This type of vitamin A is specifically active in the

221 body as retinol (alcoholic form), retinal (aldehyde form), and retinoic acid (acidic form)

222 (Delaney \& Barke, 2017; SAL, 2017). However, retinol found in foods is chemically unstable

223 though the extent of its occurrence in foods and tissues is insignificant (Bender, 2003). Each

224 form of vitamin A performs a unique function. Retinol assists reproduction and it is vitamin A's

225 major form of transport, retinal serves as an intermediate in the transformation (conversion) of

226 retinol to retinoic acid and it's also crucial in the vision system and pigment, while retinoic acid

227 acts like a hormone responsible for the growth, development, and maintenance of epithelial

228 cellular integrity, regulation of cell differentiation and immune function (FAO/WHO, 2004;

229 SAL, 2017), as well as modulates gene expression (Bender, 2003). Notably, retinal and retinoic

230 acid are derivatives of retinol. 


\section{1 ii) Vitamin $D$ :}

232 Vitamin D denotes a group of non-essential micronutrients of fat-soluble compounds

233 derived from cholesterol. The biologically active forms of vitamin $\mathrm{D}$ relevant to human is

234 synthesized from provitamin D2 (ergocalciferol) and provitamin D3 (cholecalciferol) (Zheng \&

235 Teegarden, 2014). The body (skin) synthesizes vitamin D when exposed to the ultraviolet B

236 (UVB) radiation of the sunlight. Thus, the reason for being non-essential micronutrients since it

237 can be produced by the body provided the season is right and duration of exposure in the sun

238 Delaney \& Barke, 2017), whereas vitamin D2 is obtained from plant origin, specifically plant

239 steroid, ergosterol. Both vitamins D2 and D3 are not active until activated by the body. As a

240 result of its endogenous production, vitamin $\mathrm{D}$ in its active form is classified as a hormone, as it

241 targets the bones, intestines, and kidneys (Zheng \& Teegarden, 2014; SAL, 2017). As a steroid

242 prohormone (Holick, 2004; Silva, 2017), vitamin D is of increasing global concern probably due

243 to its significance in bone health and other important systematic functions (Chung et a., 2009;

244 Verstuyf et al., 2010; Martini, Verly Jr, Marchioni \& Fisberg, 2013). Vitamin D is believed to

245 have a multitude of (biological) functions. For instance, its function in regulating the immune

246 system and cells, increasing intestinal absorption of calcium and phosphorus, helping bones to

247 grow stronger and denser (builds and maintains strong bones) as they absorb and deposit calcium

248 and phosphorus, including the mineralization of bones mediated through osteoblasts (SAL,

249 2017).

250 iii) Vitamin E:

251 Vitamin E exists in many forms of which the most active form relevant to meet human

252 requirements is alpha $(\alpha)$-tocopherol (Delaney \& Barke, 2017). Unlike other vitamins with

253 specific tasks such as being a cofactor, hormones, or participating in cell metabolism, the vitamin

$254 \mathrm{E}$ is an unsaturated fat-soluble organic compound uniquely positioned to act as an antioxidant

255 and free radical scavenger (i.e. inhibits free radical chain reactions that cause oxidative stress)

256 against lipid oxidation (Hs, Wang, Alalaiwe, Lin \& Fang, 2019). As an essential micronutrient,

257 vitamin $\mathrm{E}$ is obtained in diets of foods from plant origin as it is synthesized by plants and other

258 photosynthetic organisms only (DellaPenna, 2005; Reboul, 2017). Like other fat-soluble

259 vitamins, dietary fat is needed for the absorption of vitamin E since its transportation to the liver

260 is dependent on being packaged into lipid-rich chylomicrons in the intestinal cells (Delaney \&

261 Barke, 2017). 
262 iv) Vitamin $K$ :

263 Vitamin $\mathrm{K}$ is an essential fat-soluble organic compound (micronutrient) that belong to the

264 isoprenoid quinones (Shearer \& Newman, 2014) having cofactor activity for $\mathbb{Z}$-glutamyl

265 carboxylase (Ball, 2004). It is believed to exist in two forms, synthesized by plants and bacteria.

266 In plants, vitamin K1 which is known as phylloquinone with phytyl side chain is the only vital

267 molecular form of vitamin $\mathrm{K}$ while vitamin $\mathrm{K} 2$, which is also known as menaquinones with

268 unsaturated 5-carbon (prenyl) units is synthesized by bacteria (FAO/WHO, 2004). Vitamin K1

269 and K2 are the main circulating and storage forms of vitamin K in humans (Ottaway, 1993). On

270 the other hand, vitamin K3 (menadione) is one of the artificially produced forms of vitamin K

271 that does not occur naturally. It is in the form of a yellowish synthetic crystalline substance,

272 usually converted into an active form of vitamin K2 in the body of an animal (Jay et al., 2015;

273 Drugbank, 2021). As an essential micronutrient, vitamin $\mathrm{K}$ is not synthesized by humans and

274 therefore should be obtained from plant-based diets. Vitamin K is critical to good health as it

275 plays a significant function in bone health or formation and blood coagulation known as clotting

276 (Combs, 2008). In addition, vitamin $\mathrm{K}$ is involved in bone protein metabolism, especially

277 osteocalcin. Notably, minerals cannot interact with osteocalcin that normally forms bones

278 without vitamin K activity (SAL, 2017).

279 b) Water-soluble vitamins group

280 i) Vitamin $B 1$

281 This is the first member of B-complex vitamins known as thiamine, and a sulfur-

282 containing water-soluble type with pyrimidine and thiazole rings, linked by a methylene bridge

283 (Bender, 2003). Thiamine acts as a coenzyme (thiamine pyrophosphate) in a variety of important

284 metabolic reactions as it plays a significant role in energy metabolism, catabolizing

285 carbohydrates, proteins, and lipids into energy (FAO/WHO, 2004). It is also essential in muscle

286 and nerve activity (SAL, 2017), as the glucose that is broken down by thiamine is needed as an

287 energy source for these activities. In addition, as a key player in the synthesis of

288 neurotransmitters, it is also required for ribonucleic acid (RNA), deoxyribonucleic acid (DNA),

289 and adenosine triphosphate (ATP) synthesis (Delaney \& Barke, 2017).

290 Thiamine is very sensitive to decomposition by many factors such as heat, neutral and

291 alkaline $\mathrm{pH}$ conditions, ionizing radiation (light), sulphite during processing, and oxidation 
292 (Combs, 2008). Thiamine is obtained by humans from diets as it is mostly found in foods though

293 in a relatively low amount (Said, 2004; Combs, 2008). It is obtained from bacteria sources,

294 especially the normal microflora in the intestine and usually, it is also absorbed in that same gut

295 region (Said, 2004). Thiamine's occurrence in the diet is in the phosphorylated form, which is

296 converted to free thiamine by phosphates before its intestinal absorption. Additionally, most of

297 the thiamine produced in the large intestine by bacteria exist in its free absorbable form but the

298 total body thiamine requirement relative to the contributions from bacteria source is yet unclear

299 (Said, 2011).

300 ii) Vitamin $B 2$

301 Vitamin B2 is a member of water-soluble vitamins known as riboflavin. It supports

302 cellular antioxidant protection and plays a key role in the metabolic pathway of carbohydrates,

303 lipids, and proteins (Combs, 2008; Said, 2011). Riboflavin also discharges its functions by acting

304 as a precursor to the coenzymes, flavin mononucleotide (FMN) and flavin adenine dinucleotide

305 (FAD) which are historically referred to as nucleotides. They are involved in a wide range of

306 oxidation-reduction reactions in the intermediary cellular metabolism. As a coenzyme, it is an

307 essential component of flavoproteins (flavoenzymes), which assist in electron transfer in the

308 electron transport chain (ETC) (Said, 2011). It is believed that the coenzymes of other B-

309 vitamins (vitamin B6, niacin, and folate) rely on the actions of flavoproteins for proper

310 functioning and conversion into their active coenzyme forms (Said, 2011).

311 The riboflavin widely found in foods is exclusively bound to proteins in the form of FMN

312 and FAD (Decker, 1993; Bates, 1997; Combs, 2008). Besides being sensitive or easily destroyed

313 by ultraviolet light, vitamin B2 also acts as auxiliary molecules to help ensure the proper

314 functioning of proteins in the body (Avrutin, 2020). Like in other vitamins, riboflavin is obtained

315 from diets of plant-based and animal-based, which are processed and absorbed in the small

316 intestine (Said, 2011; Pinto \& Rivlin, 2014; SAL, 2017). Additionally, it can be obtained from

317 bacteria in the large intestine, where the vitamin is synthesized and absorbed in the same gut

318 region (Said, 2011).

319 iii) Vitamin $B 3$

320 This is another member of the water-soluble vitamin known as niacin. Niacin exists in

321 two forms, namely; nicotinic acid and nicotinamide with its biologically active forms of

322 nucleotides as nicotinamide-adenine dinucleotide (NAD) and nicotinamide-adenine dinucleotide 
323 phosphate (NADP) through which the vitamin participates virtually in all aspects of metabolism

324 (Combs, 2008). As coenzymes (NAD and NADP), niacin participates in energy-transfer

325 reactions, specifically in the metabolic reactions of carbohydrates, lipids, proteins, and alcohols.

326 Also, niacin aids in nervous system function and digestion, participates in oxidation-reduction

327 metabolic reactions, protects against neurological degeneration, and has lipid-lowering ability

328 (SAL, 2017; Delaney \& Barke, 2017; Avrutin, 2020).

329 The implication of oxidative stress in a variety of chronic or neurodegenerative diseases

330 cannot be overemphasized (Ilkhani, Hosseinie \& Saedisomeolia, 2016; Ofoedu et al., 2021). As

331 a neglected potential antioxidant micronutrient, the active form (NAD/NADP) or reduced form

332 (NADH/NADPH) of niacin have been associated with antioxidant properties via glutathione

333 redox cycle, which tends to combat oxidative stress, specifically, lipid peroxidation and

334 reperfusion oxidative injury (Ilkhani et al., 2016; Fricker, Green, Jenkins \& Griffin, 2018;

335 Gasperi, Sibilano, Savine \& Catani, 2019). Additionally, the lipid-lowering ability of niacin (for

336 example, reduction in triglycerides, low-density lipoprotein (LDL), very-low-density lipoprotein

337 (VLDL), and total cholesterol) varies according to the mode of usage, either singly or combined

338 with other medications, for instance, hydroxymethyl glutaryl coenzyme A reductase inhibitors

339 (Djadjo, 2021). Niacin's mechanism of action for its antilipolytic effect has been hypothesized to

340 be mediated through nicotinic acid receptors, which can enhance intracellular degradation of

341 Apolipoprotein B (ApoB) (that contains lipoproteins such as LDL and VLDL), by inhibiting the

342 synthesis of triglycerides (Florentin, Liberopoulos, Kei, Mikhailidis \& Elisaf, 2011; Kei,

343 Liberopoulos \& Elisaf, 2011; Djadjo, 2021).

344 Interestingly, niacin's coenzymes are involved in electron transfer in the electron

345 transport chain (ETC) during cellular respiration to make ATP and are also essential in the

346 synthesis of cholesterol and build-up of fatty acids (Said, 2011). Niacin can be biosynthesized in

347 the body from amino acid tryptophan (SAL, 2017; Delaney \& Barke, 2017). This synthesis takes

348 place only after tryptophan has met its nutritional requirement in the body. However, studies

349 have shown that there is little or no association between food high in tryptophan and niacin

350 deficiency (Delaney \& Barke, 2017). Niacin in foods is very stable to normal storage conditions

351 and other food preparation and cooking methods, for example, moist heat (Combs, 2008). The

352 vitamin is found in various foods and predominantly occurs in bound forms. For instance, in 
353 plants, it is present mostly as protein-bound nicotinic acid and as nicotinamide in animal tissues 354 (Combs, 2008).

355 iv) Vitamin $B 5$

356 Vitamin B5 is a water-soluble vitamin known as pantothenic acid which has a central role 357 in energy-yielding metabolism as a component of coenzyme A (main carbon molecule carrier in 358 a cell) moiety. It is a cofactor that carries acyl group in many enzymatic processes, acyl transfer 359 reactions (Bender, 2003), and in the biosynthesis of fatty acids (FAO/WHO, 2004; Bender, 360 2003), haemoglobin, steroid hormones, and neurotransmitters (SAL, 2017). Further, it is 361 essential for normalizing the blood lipid profiles, tissue repair, and maintenance, as well as in a 362 wound, and lesion healing (SAL, 2017). Pantothenic acid can be obtained from diets of food of 363 plant and animal origin, as well as bacterial sources, from natural microflora of the large 364 intestine (Said, 2011). The vitamin is ubiquitously distributed in many foods, which is why its 365 deficiency is rare. Interestingly, it occurs mainly in the bound forms of CoA, CoA esters, and 366 acyl-carrier proteins (Combs, 2008).

367 v) Vitamin B6

368 Vitamin B6 is an essential water-soluble vitamin occurring in three natural forms, 369 namely; pyridoxine (alcohol form), pyridoxamine (amine form), and pyridoxal (aldehyde form).

370 Vitamin B6 is essential for many biological functions such as the metabolism of three

371 macronutrients (carbohydrate, protein, and lipid), synthesis of neurotransmitters, and in a variety

372 of elimination and replacement reactions (Bender, 2003; SAL, 2017). Besides being involved in

373 the formation of red blood cells or haemoglobin synthesis, vitamin B6 coenzymes (pyridoxal

374 phosphate) plays a significant role in multiple metabolic reactions, giving the vitamin importance 375 in such diverse areas as growth, cognitive development, depression, immune function, fatigue, 376 and steroid hormone activity (Combs, 2008).

377 Vitamin B6 has been closely linked with the function of the nervous system as a result of 378 monoamine neurotransmitters generated via the amino acid decarboxylase reactions

379 (Dakshinamurti \& Dakshinamurti, 2014). The coenzyme of vitamin B6 plays a key role in a 380 valuable protein and urea metabolism (SAL, 2017) by the conversion of essential amino acid 381 methionine into cysteine (non-essential amino acid), as well as in the conversion of amino acid 382 tryptophan to niacin or the neurotransmitter serotonin (SAL, 2017). Vitamin B6 is fairly 383 widespread in plant-based and animal-based foods, thus its deficiency is not prevalent (Combs, 
384 2008). Interestingly, under acidic conditions, vitamin B6 is stable but fairly unstable in neutral

385 and alkaline conditions especially when exposed to heat or light.

386 vi) Vitamin $B 7$

387 Vitamin B7 is a water-soluble vitamin also known as biotin or vitamin H. Biotin is very

388 important in metabolic reactions such as gluconeogenesis, lipogenesis, and breakdown

389 (catabolism) of branched-chain amino acids (Bender, 2003). Biotin is essential as a coenzyme

390 that transfers carbon dioxide $\left(\mathrm{CO}_{2}\right)$, which is crucial in the catabolism of carbohydrates, proteins,

391 and fats into energy (SAL, 2017). Additionally, it functions as a coenzyme involved in many

392 cellular metabolisms and the synthesis of some non-essential amino acids. Biotin is absorbed in

393 the gut by the specific action of an enzyme, biotinidase, which releases biotin from protein

394 (Delaney \& Barke, 2017). Similarly, it is also a key player in the regulation of oncogenes

395 expression and the cellular level of the second messenger cGMP (Scheerger \& Zempleni, 2003;

396 Said, 2011). Biotin is obtained from different varieties of foods. It can also be synthesized by

397 bacteria in the colon, but in an insignificant amount (Combs, 2008; Delaney \& Barker, 2017).

398 However, biotin in food is easily destroyed by heat and unstable in oxidizing conditions

399 especially under conditions supporting lipid peroxidation (Dakshinamurti, 2005; Combs, 2008).

400 vii) Vitamin $B 9$

401 Vitamin B9 is a family of water-soluble vitamins that function in multiple forms of

402 reactions involved in coenzymes, transferring one carbon for the synthesis of DNA and in energy

403 metabolism (Bailey, da Silva, West \& Caudill, 2014) which exists in two forms, namely; folate

404 and folic acid. Vitamin B9 exists naturally as folate which has the basic molecule of 5,6,7,8-

405 tetrahydropteroylglutamate also referred to as pteroylglutamic acid or tetrahydrofolate (THF)

406 (Shane, 2009). The addition of glutamate residue via $\mathbb{V}$-peptide linkage assures that the

407 monoglutamate form of the vitamin which contains one glutamic acid molecule is converted to a

408 polyglutamate chain (varies from 5 to 8 side chain). On the other hand, folic acid is a synthetic

409 fully oxidized monoglutamate form of the vitamin that is used commercially in fortified or

410 enriched foods and supplements (Bailey et al., 2014; SAL, 2017). Folic acid (Pteroyl

411 monoglutamate) is the most stable form of folate. In addition to folate's action as a coenzyme, it

412 is essential for the growth, development, and specialization of cells of the central nervous system

413 (Delaney \& Barke, 2017), and brain development and function. Similarly, it synthesizes 
414 thymidine and purine as well as participates in several amino acid metabolisms, for example, 415 homocysteine (Said, 2011).

416 Interestingly, folate and vitamin B12 collaborate in the transfer of a one-carbon

417 compound which is the methyl group. For instance, folate's coenzyme (THF) donates its carbon

418 compound from a methyl group to vitamin B12, thereby transforming the latter into an active 419 coenzyme and as a result, catalyzes the conversion of homocysteine to methionine (SAL, 2017).

420 In other words, in the absence of vitamin B12, late in its methyl form becomes enclosed in cells, 421 and unavailable to support cell growth. Folate is widely distributed in foods of plants and animal 422 origin, although the latter is not quite a good source of folate. In most foods containing folate 423 other than folic acid, the former is easily oxidized due to its instability to oxidation under aerobic 424 conditions of storage and processing (Combs, 2008).

425 viii) Vitamin $B 12$

426 Vitamin B12 is an essential water-soluble vitamin known as cobalamin, making it the 427 only vitamin that contains metal, cobalt (Delaney \& Barke, 2017). Cobalamins are corrinoids 428 with a dimethylbenzimidazole nucleotide attached to the $\mathrm{D}$ ring and chelating the central cobalt 429 atom. In nature, vitamin B12 occurs in two forms, namely: hydroxocobalamin and 430 aquacobalamin, where hydroxyl and water groups are respectively attached to the cobalt. 431 However, the synthetic form of vitamin B12 is found in enriched/fortified foods, as well as in 432 such supplements as cyanocobalamin, which has cyanide attached to the cobalt. Noteworthily, 433 aquacobalamin, hydroxocobalamin, and cyanocobalamin are enzymatically activated in all 434 mammalian cells to the methyl or deoxy adenosylcobalamin (FAO/WHO, 2004). In mammalian 435 cells, methionine synthase and methyl malonyl coenzyme (CoA) mutase are the two vitamin 436 B12-dependent enzymes that are necessary for its metabolic processes (Scott \& Rodriquez, 2000; $437 \mathrm{FAO} / \mathrm{WHO}, 2004)$.

438 As an important coenzyme, vitamin B12 is necessary for the breakdown of protein and 439 fat, synthesis of haemoglobin, activation of folate's coenzyme function (Delaney \& Barke, 440 2017), in cellular division and growth (Combs, 2008), and participates in the conversion of 441 homocysteine to methionine (SAL, 2017). Further, in dietary terms vitamin B12 is not derived 442 from plant-based foods; therefore, humans and animals that consume strictly vegetarian diets are 443 very likely to have the suboptimal intake of vitamin B12 except where the plant-based foods 
444 have been fortified or enriched (SAL, 2017). On the other hand, vitamin B12 is found in the 445 tissues of animals and can also be synthesized by bacteria (FAO/WHO, 2004; Combs, 2008).

446 ix) Vitamin $C$

447 Vitamin $\mathrm{C}$ is a family of water-soluble compounds also known as ascorbate in dietary 448 terms but occurs in two forms, namely; ascorbic acid (reduced form) and dehydro-L-ascorbic 449 acid (DHAA) (oxidized form) (Said, 2011). Chemically, it is a six-carbon lactone that is 450 synthesized from glucose by many animals (FAO/WHO, 2004) but cannot be synthesized by 451 humans because of a single enzyme deficiency (Combs, 2008). Whether or not it is synthesized, 452 ascorbic acid is an important vitamin for several physiological functions. As a cofactor in 453 multiple integral metabolic reactions, vitamin $\mathrm{C}$ is essential in the synthesis of collagen, defense 454 against infection and inflammation, as well as maintaining metal ions, for example, iron and 455 copper, in their reduced states (FAO/WHO, 2004; Delaney \& Barke, 2017). Vitamin C plays an 456 important role as a catalyst and redox cofactor in a wide variety of biochemical processes and 457 reactions (Johnston, Steinberg \& Rucker, 2014).

458 Besides acting as a cofactor in helping specific enzymes do their functions properly, 459 ascorbic acid has a protective role of acting as an antioxidant (reducing agent or electron donor) 460 in tissues and plasma against free radicals (FAO/WHO, 2004; Combs, 2008; SAL, 2017). The 461 ability of vitamin $\mathrm{C}$ to freely donate electrons makes it an effective scavenger against reactive 462 oxygen species and reactive nitrogen species (Delaney \& Barke, 2017), as well as in arresting 463 lipid oxidation. Additionally, it supports the recycling and regeneration of $\alpha$-tocopherol (vitamin 464 E) (Combs, 2008). In addition to vitamin C's antioxidant capacity, it acts as an electron donor to 465 several enzymes (Combs, 2008), necessary for signalling molecules in the brain, some hormones, and amino acids (Delaney \& Barke, 2017). It is also essential in the growth and repair of tissues in all body parts.

\section{Metabolic Functions and Sources of Vitamins}

Indeed, vitamins play key roles in the physiological processes of our bodies and perform unique metabolic functions that are dependent on their chemical reactivity and cellular or tissue distribution. The various functions of vitamins form the basis for their relevance in health and nutrition. Generally, the metabolic functions of vitamins are specifically categorized into

473 antioxidants (vitamins A and E), coenzymes (vitamins A, K, C, B1, B2, B3, B5, B6, B7, B9, and 474 B12), hormones (vitamins A and D), and electron donors/acceptors (K, C, B5, B3, and B2), and 
475 gene transcription elements (Combs, 2008). While most vitamins require metabolic activation or 476 conversion to perform their physiological role in biological systems, few vitamins function 477 without any kind of metabolic conversion or association with an enzyme. The metabolic 478 modification of food-sourced vitamins into active forms utilized during cellular metabolism may 479 cause significant transformation on the chemical properties and/or structure of the vitamin which can greatly affect their nutritional potency. In addition, summarized in Table 2 are the specific

481

482

483

484

485

486

487

488

489

490

491

492

493

494

495

496

497

498

500

501

502

503 metabolic functions of vitamins when considered individually.

Vitamins exist naturally in different forms. Some are synthesized by microorganisms (intestinal bacteria) in the gut region, for example, vitamins K2, B1, B9, and B12 (Gorbach, 1996; Hill, 1997; Uribe, Garcia-Galbis \& Espinosa, 2017; Chen, Michalak \& Agellon, 2017), while others are predominantly found in foods of plant origin only, animal origin only, or both plant and animal origin. Also, some vitamins are synthesized in the body in varying concentrations probably through the metabolic transformation from amino acids and/or directly produced by the skin. For example, the endogenous synthesis of niacin and vitamin $\mathrm{D}$ from the amino acid tryptophan and exposure of the skin to the sun respectively (Bendeer, 2003; Nair \& Maseeh, 2012). Generally, the vitamins synthesized endogenously are not sufficient to meet daily needs, so dietary intake is required. (Combs, 2008: Uribe et al., 2017) Moreover, the amount of vitamins in food is dependent on its source, the form it occurs naturally, and its actual distribution across various foods. However, no single food source contains all the vitamins and inadequate or suboptimal consumption of vitamins results in deficiencies. This implies that a variety of food is therefore needed to meet the vitamin requirement of the body (SAL, 2017). Table 3 summarizes the major food sources of vitamins available for the human diet.

\section{Absorption of Vitamins}

Vitamins are fundamentally absorbed in the small intestine and their bioavailability is dependent on the food composition of the diet. Basically in human nutrition, bioavailability by way of definition is the proportion of the amount of vitamin in ingested food that is absorbed in the intestines and utilized at the cellular level by the body (Ball, 2004). In this context, vitamin utilization entails the transport of absorbed vitamins to tissues, uptake by cells, and subsequent fate of the vitamin which could be converted into a form required to perform some biochemical 
504 function. The flow process of vitamin absorption is briefly described in Figure 3. It shows how

505 fat- and water-soluble vitamins gets to target cells when ingested from food.

506 a) Factors that influence vitamin absorption

507 To reiterate, absorption of a vitamin depends on how the vitamin exists relative to its 508 chemical and physical state within the food matrix (Ball, 2004; Combs, 2008). Specifically, in

509 foods, some vitamins occur as their coenzyme derivatives, underivatized form with a proportion

510 linked with specific binding-proteins, and chemically bound complexes with some other

511 components in the food matrix which cannot be absorbed or utilized until the vitamins are

512 released from their bound forms by enzymes in the intestinal tract or tissues.

513 However, the complex nature of a food matrix in terms of its composition, structure, and

514 component interactions, for example, vitamin-vitamin interaction, vitamin-mineral interaction,

515 etc., can have a potential impact on vitamin absorption, utilization, and cellular uptake. In other

516 words, food component interaction with vitamins may exhibit lower absorption efficiency as

517 well as retard or enhance the absorption of vitamins compared with unbound (free) ones already

518 ingested in the tablet form (i.e. supplements) without co-extractive. Additionally, adequate

519 quantities of water and dietary fat are vital for the absorption of the water-soluble and fat-soluble

520 vitamins respectively. According to a clinical trial report by Reboul, the presence of long-chain

521 fatty acids reduced the absorption of vitamin D3 when administered at physiological doses in rats

522 (Reboul, 2017). This report was strengthened by another trial report that monosaturated fatty

523 acids enhanced the effectiveness of vitamin D supplementation whereas polyunsaturated reduced

524 it. Interestingly, studies have shown that interaction amongst vitamins can influence its

525 efficiency of absorption. A study conducted by Goncalves et al., (2015) shows that vitamin E

526 significantly enhanced vitamin A uptake at medium and high concentrations up to $40 \%$ while

527 vitamin $\mathrm{D}$ absorption was significantly reduced by vitamin $\mathrm{E}$ at medium (-15\%) and high (-17\%)

528 concentration as well as by vitamin A at high concentration (-30\%).

529 Furthermore, the nature (physical state) of food can also influence vitamin absorption

530 efficiency. For example, a carotenoid present in fibrous plant material with poor digestibility has

531 been shown to exhibit low bioavailability relative to vitamin A (Riedl, Linseisen, Hoffmann \&

532 Wolfram, 1999; Lattimer \& Haub, 2010). It is important to note that extrinsic factors (differing

533 biopotencies of vitamin forms, dietary effects, losses during storage, processing, and/or cooking)

534 and intrinsic factors (state of health and age-related differences in gastrointestinal function) may 
535 also influence the efficiency of vitamin absorption (Combs, 2008). For instance, in terms of

536 dietary effects, the composition of diets and meals would influence the absorption of some

537 vitamins by affecting intestinal transit time and/or the enteric formation of mixed micelles

538 (Lattimer \& Haub, 2010; Muller, Canfora \& Blaak, 2018; Carreiro \& Buhman, 2019; Pulgisi,

539 2019). This was found in a study that reported poor absorption of vitamin A and pro-vitamin A

540 carotenoids from very low-fat diets Roodenburg et al. (2000) showed that $3 \mathrm{~g}$ of fat per meal

541 would suffice for optimal absorption of some pro-vitamin A carotenoids. However, Brown et al.,

542 (2004) found that $29.5 \mathrm{~g}$ of fat per meal would not suffice for optimal absorption. These two

543 studies would, therefore, suggest that other factors such as individual health status, physiological

544 effects, and interactions between vitamins and other food components could be responsible for

545 such variations. While it has been established that fat-soluble vitamins may not be fully

546 absorbed from low-fat diets, the minimum amount of fat required to facilitate proper absorption

547 of lipophilic vitamins is still not clear. Other factors that may interfere with the physiological

548 absorption mechanism of vitamin includes alcohol and drugs, presence of gastrointestinal

549 disorders or diseases (parasitic infections, malignant diseases, etc), and metabolic requirement

550 (Ball, 2004).

551 b) Absorption of water-soluble vitamins

552 The physical and chemical properties of vitamins play an integral role in the absorption

553 of water-soluble vitamins. The polar environment of the intestinal lumen makes the absorption of

554 water-soluble vitamins more direct and suitable for the absorptive surface of the gut due to its

555 hydrophilic nature (Combs, 2008). Some water-soluble vitamins such as vitamin C, pantothenic

556 acid, niacin, folate, thiamine, vitamin B12, biotin, and vitamin B6 are absorbed into the

557 bloodstream by the action of passive diffusion while others such as riboflavin which may not

558 undergo simple diffusion are absorbed through a carrier-dependent mechanism as a means of

559 overcoming concentration gradient (Halsted, 2003; Said, 2011). In other words, at high

560 concentrations (doses), several vitamins are absorbed by simple diffusion and by specific carriers

561 or carrier-dependent mechanisms at low concentrations (doses).

562 c) Absorption of fat-soluble vitamin

563 As earlier indicated in this paper, the physical and chemical properties of vitamins play

564 an integral role in their absorption. However, the hydrophobic nature of fat-soluble vitamins 
565 makes them insoluble in the aqueous environment of the alimentary canal, but instead are meant

566 to dissolve in other lipid materials. As a result of gastric churning and mechanical actions of

567 mastication in the upper portion of the gastrointestinal tract, the fat-soluble vitamins are

568 solubilized in the bulk lipid phase of the emulsions formed from dietary fats (Borel, 2009).

569 Further, due to the large size of emulsion oil droplets (for example, $100 \mathrm{~nm}$ ), access to the

570 absorptive surfaces of the small intestine that is vital to enhance diffusion into the non-polar

571 (hydrophobic) environment of the brush-like projections of intestinal mucosal cells may be

572 inhibited (Rigby \& Schwarz, 2001). Hence, lipase enzymes secreted via the pancreatic duct of

573 the pancreas binds to the surface of the emulsion oil droplets and breaks down triglycerides from

574 the bulk of the lipid material to yield fatty acids and $\beta$-monoglycerides that can dissolve to some

575 extent in the aqueous environment as a result of its charged groups and strong polar regions.

576 The products of the abovementioned process involve a long-chain hydrocarbon with non-

577 polar regions, which spontaneously operate with the bile salts (of similar properties) to form

578 mixed micelles. There is an essential small aggregate composition of free fatty acids, bile salts,

579 and $\beta$-monoglycerides that have an interior with a non-polar region and an exterior with a polar

580 (charged) region, within the aqueous phase (Meydani \& Martin, 2001). The hydrophobic core of

581 the mixed micelles dissolves the fat-soluble vitamin and other associated lipid substances that are

582 non-polar. Mixed micelles are generally too small (4-10 $\mathrm{nm}$ in diameter) and can gain

583 proximity to the border brush membrane of the intestinal mucosa, thus enhancing the diffusion of

584 their contents into and across membranes (Combs, 2008).

\section{Vitamins utilization: Transport and cellular uptake}

586 Like in vitamin absorption, the post-absorptive transport mechanism of vitamins also

587 differs in accordance with their unique physical and chemical properties. Additionally, the

588 dissolution of vitamins in a polar environment of blood plasma and lymph is another determinant

589 factor for the transport of vitamins from its absorption site (small intestine) to the peripheral

590 organs and liver (Albahrani \& Greaves, 2016). As a result of the insolubility of fat-soluble

591 vitamins in these transport environments, they rely solely on carriers that are soluble in these

592 aqueous phases for their transport (Gil, Plaaza-Diaz \& Mesa, 2018). These vitamins, however,

593 are coupled with blood lipid-rich chylomicrons (lipoprotein) that are largely synthesized in the

594 intestinal mucosal cells, which serve to transport the absorbed fat-soluble vitamins to other

595 lipoprotein carriers such as very-low-density lipoproteins (VLDL) and high-density lipoproteins 
596 (HDL) while some (vitamin A and D) are transported by specific binding proteins (retinol597 binding proteins (RBP), transcalciferin, cellular retinoic acid-binding protein (CRABP), cellular 598 retinol-binding protein (CRALBP), and vitamin D receptor) from the liver to peripheral tissues 599 (Feingold, 2000; Comb, 2008; Zhang, Zhao \& Huang, 2012; Bouillon, Schuit, Antonio \& 600 Rastinejad, 2020). Lipoproteins are involved in the lipid-soluble vitamin transport given its 601 molecular characteristics of having a lipid-protein combination, with the solubility properties of 602 protein that exhibits dissolution in aqueous environment of the blood plasma (Saba \& Oridupa, 603 2012; Axmann, Strobl, Plochberger \& Stangl, 2019; Christie, 2021).

604 However, for the water-soluble vitamins, while several absorbed vitamins (niacin, 605 vitamin $\mathrm{C}$, riboflavin in the form of flavin mononucleotide, biotin, folate, and pantothenic acid) are freely transported in plasma solution via the erythrocyte membranes, some water-soluble vitamins (free riboflavin and pyridoxine) are transported by weak, non-specific binding with albumin and immunoglobulins (for free riboflavin only) which may be displaced by other compounds that can also bind to the protein. Others (vitamin B12 and riboflavin) are carried by specific binding proteins such as flavoproteins, riboflavin binding protein, and transcobalamin I, II, and III (Combs, 2008; Gil et al., 2018). The absorption mechanism and post-absorptive transport of vitamins in the body are shown in Table 4.

The extent and actual rate of cellular uptake of food-sourced vitamins vary due to some

614 factors already mentioned above (differing losses, physiological effects, varying biopotencies, 615 dietary effects, and health status) (Combs, 2008; Uribe et al., 2017). As a result, the human body 616 would not entirely utilize all the vitamins in foods. The quantification of the total amount of 617 food-sourced vitamins (obtained by analysis), therefore, would not equate and/or guarantee the 618 actual nutritional value of those vitamins, because of these absorption impediments at cellular 619 level (Zuvarox \& Belletieri, 2021; Ruiz, 2021). In terms of vitamin retention and distribution, 620 generally, their physical and chemical properties also determine the site of storage or 621 distribution. Overall, the fat-soluble vitamins are significantly retained in the body and tend to be 622 stored in lipid-rich tissues like the liver and adipose. Through enterohepatic circulation, fat623 soluble vitamins would be excreted with the faeces, except for some water-soluble metabolites of 624 vitamin A (retinoic acid), vitamin E (Simon metabolites, $\alpha$-tocopheronic acid and its lactone), 625 and vitamin $\mathrm{K}$ intermediate (menadione), also excreted in the urine despite being retained in 626 lipophilic environment (Wallert et al., 2014; Shearer \& Newman, 2014). In contrast, the water- 
627 soluble vitamins appear not to be retained in significant amounts in the body and are rapidly

628 excreted through urine. Interestingly, an exception applies to vitamin B12 which can accumulate 629 in the liver in significant quantities under normal circumstances (Gil et al., 2018).

\section{Characteristic interactions associated with food-sourced vitamins}

Nowadays, increased nutritional awareness has significantly influenced the approach to

632 food production and consumption towards a personalized optimal health experience rather than

633 its original archaic perspective - food for survival. Specifically, food is a complex system with

634 multitudes of variable chemical components (compounds) coexisting together (Sikorski \&

635 Haard, 2007). Foods with such complex systems are bound to have ubiquitous molecular

636 interaction between macronutrients, micronutrients and even ions, exhibiting different

637 interactivities such as hydrophobic interaction, covalent bonding, hydrogen bonding (bridges),

638 electrostatic or ionic interaction, $\pi-\pi$ stacking, and coordination force, among others (Gao et al.,

639 2016). Food-sourced vitamins are diet-oriented and of plant and animal origin. Besides having

640 less potential for toxicity, food-sourced vitamins are important because of their distinct

641 advantage over vitamins in dietary supplement. The former is naturally associated with other

642 food substances of beneficial effect that may enhance their absorption and utilization at the

643 cellular level (Weininger, 2021). Though dietary supplement cannot replace a healthy diet, there

644 seems to be a conflicting compromise between food-sourced vitamins, as some components

645 present in a food matrix can enhance vitamin absorption, others may hinder its utilization in the

646 body even up to cellular level. These phenomena in the food matrix have arisen due to

647 interactions between vitamin-vitamin, as well as vitamin-mineral interactions. In other words, the

648 molecular interaction among food components forms the basis for differences in the stability and

649 functional characteristics of food-sourced vitamins.

650 a) Vitamin-vitamin interaction

651 Multiple studies have shown that a combination of some B-complex (thiamine, riboflavin, folic

652 acid, and cyanocobalamin) and vitamin $\mathrm{C}$ can produce detrimental effects. Most of these

653 interactions usually occur in beverages fortified with these vitamins or when vitamins are used to

654 restore food products presented in a liquid state such as fruit juices or soft drinks (Paquin, 2009).

655 The mutual interaction amongst these five vitamins has been established, as the principal ones

656 are briefly discussed below.

657 - Vitamin B12 - folic acid: 
658 The metabolic interaction between the two vitamins occurs during a deficiency of either vitamin

659 in the catalytic transformation of homocysteine to methionine by the methionine synthase

660 enzyme, which results in anaemia (Shane, 2008; Kumar et al., 2017). Studies have shown that

661 there is a reduction in the activity of the vitamin B12-dependent methionine synthase enzyme

662 with a proportionate deficiency in vitamin B12. This invariably results in a deficiency of

663 functional folate because a higher concentration of folate has been confiscated or trapped as 5-

664 methyl-tetrahydropteroyl-poly-glutamate (Mahmood, 2014). Additionally, the combined effect

665 of vitamin 12 and folic acid deficiencies in fish (Labeo rohita) was found to increase the

666 development of anaemia, making it more pronounced.

667 - Vitamin C - folic acid:

668 The metabolic interaction between the two vitamins initiates bond breakage of folic acid in a 669 solution containing vitamin $\mathrm{C}$ and folic acid, as a result of the reducing property of vitamin $\mathrm{C}$.

670 The cleavage of folic acid has been demonstrated to be slowest in a very low acidic medium ( $\mathrm{pH}$ $6716.56-6.70)$ and most rapid in a high acidic medium ( $\mathrm{pH} 3.0$ - 3.3) (Ottaway, 1993;

672 Schnellbaecher, Binder, Bellmaine \& Zimmer, 2019; Wusigale \& Liang, 2020).

673 - Vitamin B12 - Vitamin C:

674 The stability of vitamin B12 vitamers (hydroxocobalamin, methylcobalamin, and

675 cyanocobalamin) is affected by interaction with vitamin C (ascorbic acid) in an aqueous solution.

676 The instability is owed to the degradation losses of these vitamers in the presence of ascorbic

677 acid which appears to be $\mathrm{pH}$-dependent, as higher losses are recorded at low acid to neutral $\mathrm{pH}$

678 while lower losses are obtained in a very low acid range (Ottaway, 1993). According to Lie,

679 Chandra-Hioe \& Arcot (2019), methylcobalamin exhibited the greatest degradation losses (70-

$68076 \%$ ) in the presence of ascorbic acid, followed by hydroxocobalamin and cyanocobalamin.

681 However, the degradation of vitamin B12 is maximum at $\mathrm{pH} 5.0$ which is an indication of peak

682 interaction between vitamin B12 and ascorbic acid. The increased interaction (degradation) of

683 vitamin $\mathrm{B} 12$ at $\mathrm{pH} \leq 5.0$ is a result of the gradual ionization of ascorbic acid to form the

684 ascorbate monoanion while the reduced interaction at $\mathrm{pH} \geq 5.0$ is owed to the loss of ascorbate

685 monoanion by oxidation (Ahmad et al., 2014).

686 - Vitamin B12 - Thiamine:

687 Studies have shown that the interaction between vitamin B12 and thiamine are mutually

688 dependent. Vitamin B12 vitamers have been demonstrated to be unstable in the presence of 
689 thiamine by exhibiting degradation losses of about $48 \%$ for methylcobalamin, $24 \%$ for

690 hydroxocobalamin, and 6\% for cyanocobalamin (Lie et al., 2019). The degradation of vitamin

691 B12 is attributed to the formation of 4-methyl-5-( $\beta$-hydroxyethyl) thiazole during thiamine

692 decomposition. In other words, the rate of vitamin B12 breakdown increases with the

693 degradation of thiamine (Ottaway, 1993).

694 - Riboflavin-vitamin C:

695 Riboflavin has been found to act as a light-energy receptor, catalyzing the oxidation of ascorbic 696 acid when exposed to light. This reaction suggests the increased rate of vitamin $\mathrm{C}$ degradation 697 (loss) in food products like milk in the presence of sunlight (Ottaway, 1993; de La Rochette et 698 al., 2000). This implies that photo-oxidation of vitamin C is significantly reduced in the absence 699 of riboflavin (Yoshimoto, Kohara, Sato, Ando \& Ichihashi, 2020).

700 - Riboflavin-folic acid:

701 The interactive effect of riboflavin and folic acid is significantly influenced by $\mathrm{pH}$ and light, 702 which results in the degradation of folic acid by oxidation reaction (Ottaway, 1993). In other 703 words, the extent of photo-degradation of folic acid in the presence of riboflavin is $\mathrm{pH}-$

704 dependent, since riboflavin's stability is also pH-dependent (Akhtar, Khan \& Ahmad, 2000). The 705 interaction between riboflavin and folic acid appears to be enhanced as $\mathrm{pH}$ approaches neutrality 706 from the acidic region since maximum degradation was recorded between $\mathrm{pH} 6.2$ - 6.5.

707 Moreover, as $\mathrm{pH}$ increases towards the alkaline region, the interaction of riboflavin with folic acid is greatly suppressed, because of nucleophilic attack on riboflavin, thereby resulting in a 709 decrease in the rate of degradation of folic acid (Akhtar et al., 2000).

- Thiamine-Folic acid:

711 The mutual interaction between these vitamins has been shown to have a great influence on folic 712 acid stability. The degradation products of thiamine, especially hydrogen sulfide can accelerate 713 the decomposition rate of folic acid in solutions (Schnellbaecher, Biner, Bellmaine \& Zimmer, 714 2019). This reaction occurs particularly between the low acidic to neutral $\mathrm{pH}$ range $(\mathrm{pH} 5.7$ -

715 7.0) (Ottaway, 1993). Some studies have also shown that the presence of UV light significantly 716 promotes folic acid degradation (Schnellbaecher et al., 2019).

- Riboflavin-Thiamine:

718 The mutual interaction between riboflavin and thiamine has been found to result in the oxidation 719 of thiamine by riboflavin, leading to the formation and precipitation of thiochrome in an alkaline 
720 environment. However, this reaction is predominantly found in solutions containing only the B-

721 vitamins (Ottaway, 1993). On the other hand, in solutions containing thiamine, riboflavin and

722 ascorbic acid, an alteration in riboflavin is seen by the reaction of thiamine (in the form of

723 thiamine hydrochloride) in high concentration (relative to riboflavin) results in the oxidative

724 action of thiamine by riboflavin, to form and precipitate chloroflavin as the degradation product

725 of riboflavin (Schnellbaecher et al., 2019).

726 b) Vitamin-mineral interaction

727 The interaction of vitamins and minerals has been reported in different metabolic

728 situations, with emphasis on the nutritional importance these interrelationships provide,

729 specifically in the maintenance of vital physiological role and biochemical processes that are

730 crucial for human living. This mutual interaction can perform its biochemical-physiological

731 function in various ways such as the action of minerals on vitamin metabolism, the action of

732 vitamin on mineral metabolism, and/or the action of both micronutrients in cellular protection

733 (Vannucchi, 1991).

734 Briefly, zinc has been found to significantly influence and participate in numerous

735 aspects of vitamin A metabolism such as in its absorption, transportation, and utilization

736 (Christian \& West, 1998). However, it is well-known that vitamin D enhances intestinal

737 absorption of phosphate and calcium, stimulates mobilization of bone calcium, increases the

738 blood concentration of calcium, as well as enhances renal reabsorption of calcium in the distal

739 tubule (DeLuca, 1986; Ernst, 2016; Bowen, 2020). Further, vitamin E and selenium function

740 together to protect biological membranes against lipid peroxidation. Both micronutrients have

741 been reported to participate in the prevention of nutritional muscle degeneration known as

742 muscular dystrophy (Ottaway, 1993). Vitamin C interacts with iron to enhance adequate

743 absorption of iron from diets. The interaction gives rise to the formation of an iron chelate

744 complex at acid $\mathrm{pH}$, which enhances iron solubility in the small intestine, thereby increasing its

745 utilization in the duodenum (Beck, 2014; Li et al., 2020). On the other hand, the synergistic

746 action of vitamins and minerals in the protection of organism at the cellular level has been

747 recorded for vitamin E, C, carotenoid and selenium, as well as other important trace elements as

748 an antioxidant component in diets. Specifically, these indispensable antioxidant vitamins and

749 selenium, interact to protect tissues from free-radical degradation by quenching active (singlet) 
750 oxygen species, sequestering elements by chelation, and scavenging reactive oxygen species

751 (DeLaval, 2007; McDowell, Wilkinson, Madison \& Felix, 2007; Ofoedu et al., 2021).

752 c) Other interactions

753 Besides vitamin-vitamin and vitamin-mineral interactions, vitamins can also interact with

754 series of other ingredients or components in food, which may affect its stability over a period.

755 The rate of vitamin deterioration either by complete or partial loss is influenced by i.)

756 Temperature ii.) Moisture iii.) Oxygen iv.) Light v.) $\mathrm{pH}$ vi.) Oxidising and reducing agents viii.)

757 Other food components such as Sulphur dioxide viii.) Drug (for vitamin supplements) ix.)

758 Combinations of the above (Godoy, Amaya-Farfan \& Rodriguez-Amaya, 2021). Amongst these

759 factors, temperature, moisture, oxygen, $\mathrm{pH}$, and light appears to be the most important factors

760 that affect vitamin stability in food.

761 Furthermore, as a heterogeneous group of a chemical compound, vitamin stability varies

762 from being relatively stable, for example, in vitamin B3, to relatively unstable, in vitamin B12

763 which is unstable in alkaline and acid solutions, as well as degraded by light (highly

764 photosensitive) and oxidizing or reducing agents. However, vitamin degradation can also occur

765 during processing, specifically to foods subjected to heat treatment, and naturally during storage,

766 for example, during the gradual loss of vitamin $\mathrm{C}$ content in packaged foods stored over time. As

767 a result of this, food products are subjected to vitamin enrichment or fortification (Ottaway,

768 1993). The interactions between food-sourced vitamins with other components (both intrinsic

769 and extrinsic factors) are briefly illustrated in Figure 4. It shows how some factors such as heat

770 (temperature), light, minerals, vitamins, $\mathrm{pH}$, oxygen, and water can interact with food-sourced

771 vitamins.

772 Vitamin Deficiencies

773 Vitamin deficiency also known as avitaminosis is a well-known nutritional-oriented

774 situation that occurs when the human body gets deprived of certain amounts (of vitamins)

775 relative to its needed requirement (Sinha, 2003; Blanco \& Blanco, 2017). Essentially, if the

776 human body were to maintain an adequate vitamin status, there are a variety of vitamins that

777 have to be supplied in different amounts. This has to come from a balanced diet, which is

778 necessary since no single food source possesses all the required vitamins (FAO/WHO, 2019).

779 Table 5 shows that vitamin deficiency can cause a variety of health-related problems. Further, 
780 vitamin deficiency is categorized in two ways, namely: primary and secondary deficiencies

781 (Combs, 2008). Specifically, the primary deficiency refers to when the reduction in vitamin

782 status occurs as a result of failures to ingest adequate quantities of the vitamin necessary to meet

783 physiological needs. On the other hand, secondary deficiency refers to when a reduction in

784 vitamin status is owed to failure to absorb or utilize a vitamin post-absorptively, possibly due to

785 age or health status (Johnson, 2020).

786 The potential causes of vitamin deficiency in humans would vary across individuals,

787 cultural groups, and beliefs. In some cases, also, it can be linked to psychosocial and

788 technological reasons such as poor food habits, poverty, ignorance, lifestyle as well as lack of a

789 balanced diet (Singh \& Singh, 2008). Additionally, the lack of vitamin-rich foods (consumption

790 of highly refined foods), vitamin destruction (during storage, processing, and cooking), food

791 taboos and fads, apathy (lack of incentive to prepare adequate meals), and anorexia (dental

792 problems, homebound elderly, infirm) can also be listed to contribute towards vitamin-associated

793 challenges across individuals (Combs, 2008; Carr \& Rowe, 2020). Besides, deficiencies linked to

794 biological causes can also include poor digestion (absence of stomach acid), malabsorption,

795 increased metabolic need, impaired metabolic utilization, and increased vitamin excretion

796 (Tsiaras \& Weinstock, 2011; Griffiths, 2013).

797

798

\section{Vitamin Toxicities}

799

Compared to vitamin deficiency, the situation of vitamin toxicity is rare. This is because

800 it is well understood that the human body can remove excess vitamins, like water-soluble

801 vitamins, which are not stored. However, vitamin toxicity is still a problem, and of great concern,

802 especially in the like of megavitamin treatment (Evans \& Lacey, 1986; Sander, 2002). This was

803 what Davidson (1984) referred to as an offshoot of orthomolecular medicine wherein symptoms

804 are treated with massive doses of vitamins. Although megavitamin treatment would be justifiable

805 in reality only for a few conditions, vitamins in large doses via self-medication would result in

806 severe toxic complications. There is ample evidence of serious toxic effects of megavitamin

807 treatment, for example, in the United States where a substantial number of adults have treated

808 themselves (Davidson, 1984).

809 Table 6 reveals vitamin toxicities and we can see there are serious human health

810 implications. Briefly, situations of toxicities can arise in both fat- and water-soluble vitamins 
811 (Evans \& Lacey, 1986; Buehler, 2011; Delaney \& Barke, 2017; Picincu, 2021). For instance,

812 vitamin B7 (biotin) would have no direct toxicity, although not impossible if too many biotin

813 supplements are taken (Carlin \& Turner, 2018; Anon., 2021a). However, high circulating levels

814 of biotin can interfere with many commercially available immunoassays that utilize the

815 interaction involving streptavidin (Anon., 2021b). It should be noted that when taking a vitamin

816 B complex, more caution is required with vitamins B5 and B6 considering that the former may

817 cause vascular dilation, itching, nausea, headache, and allergies (Anon. 2021b). However, some

818 reports on the toxicity of Vitamin B6 and vitamin C claimed they can respectively cause nerve

819 impairment and gastrointestinal upset, as well as diarrhoea. On the other hand, there is a high

820 chance of fat-soluble vitamins being toxic to the body especially with an intake of supplements

821 since fat-soluble vitamins are stored in the liver (Delaney \& Barke, 2017).

822 Studies have shown that high levels of vitamin A known as hypervitaminosis A causes

823 dry itchy skin, loss of appetite, swelling of the brain, and joint pain as well as liver damage, and

824 coma in severe cases (Delaney \& Barke, 2017). Of very important concern has been the vitamin

$825 \mathrm{D}$, where its excess in serum plasma has been defined as a level greater than 150 to $250 \mathrm{ng} / \mathrm{ml}$,

826 and where its intoxication would involve levels greater than $375 \mathrm{ng} / \mathrm{ml}$. This brings the situation

827 of Hypervitaminosis D, which is presented with such health implications as abdominal pain,

828 cardiac arrhythmias, hypercalcemia, and hypovolemia from renal sodium and water losses,

829 neuropsychiatric disturbances, as well as suppressed parathyroid hormone level (Charen \&

830 Harbord, 2020). In particular, hypercalcemia is considered among the key situations arising from

831 vitamin D toxicity. Other early symptoms of vitamin D toxicity include gastrointestinal disorders

832 like anorexia, diarrhoea, constipation, nausea (Alshahrani \& Aljohani, 2013). In addition, there

833 are three major hypotheses believed to be associated with vitamin D toxicity, which includes: 1)

834 Raised plasma 1,25[OH]D concentrations result in increased intracellular 1,24[OH]D

835 concentrations; 2) Vitamin D intake raises plasma 25[OH]D levels to concentrations, which

836 exceed the DBP binding capacity, and free 25[OH]D directly affecting the gene expression once

837 it enters target cells; 3) Vitamin D intake that raises the concentrations of many vitamin D

838 metabolites (Alshahrani \& Aljohani, 2013).

839 Can Vitamin Requirements be met by Food-based Approaches?

840 It is well-known that available foods in a region are determined by the agricultural

841 practices, ecological, climatic, socio-economic and cultural factors that influence the dietary 
842 pattern of the people (Caswell \& Yaktine, 2013; Singh \& Singh, 2017; Tandzi \& Mutengwa,

843 2020). Currently, in developed nations, almost all the nutritional needs of their population groups

844 are met or even exceeded by dietary patterns, but that is not the case in developing or under-

845 developed nations where food choices are restricted due to limited food production capacity,

846 poor purchasing power, and/or abnormal cultural practices such as food taboos, fads, and

847 fallacies (FAO, 2001; McNamara \& Wood, 2019). In view of this, nutritional needs are met

848 when people access a variety of nutritious foods in sufficient amount.

849 Importantly, through a combination of variety of foods in different proportions, a healthy

850 diet can be achieved. To be able to meet the nutritional requirement, ascertaining the range of

851 specific food intake in a particular combination would be difficult, given the population density,

852 economic constraint, and level of food production in a certain ecology which may restrict

853 appropriate nutritional adequacy (WHO, 2003; Lietzmann, n.d.). Therefore, the formation of a

854 food-based approach that does not only consider energy and protein adequacy but also an avenue

855 that can meet the nutrient requirement and micronutrient density of the diet through a

856 combination of various foods is very fitting (de Ridder, Kroese, Evers, Adriaansse \& Gillebaart,

857 2017; FAO/WHO, 2019). This can be achieved by discovering diet-related public health

858 problems (malnutrition or certain deficiencies) in a locality or community and developing

859 appropriate dietary guidelines.

860 Further, diet-related public health problem or micronutrient (vitamin) deficiency in most

861 population groups especially in the developing countries is largely due to subsistence

862 consumption of cereal grain or root and tuber-based diets as staples, which provide energy and

863 protein with inadequate amino acid balance, but very limited essential micronutrients (FAO,

864 2001). The inclusion of a high micronutrient density diet such as pulses, fruits and vegetables

865 (including green leafy vegetables) into staple foods is the most fitting way of combating

866 micronutrient/vitamin deficiency, and ensuring optimal nutrition for the population group

867 (WHO/FAO, 1996; Tapsell, Neale, Satijia \& Hu, 2016). In addition, to meet adequate vitamin

868 requirement of the body, different combination of foods from both plant and animal origin must

869 be ingested to attain a healthy diet lifestyle. Studies have shown that foods of animal origin

870 contain about $92 \%$ of the entire vitamins while that of plant-origin contain about $77 \%$ of total

871 vitamin. Since no single food source contains all the vitamins, a combination of different foods 
872 (especially from plant and animal sources) in adequate quantities of water and oil, are vital to

873 meet the body's vitamin requirement.

874 Food-sourced Vitamins: COVID-19 and Era of Micronutrient Deficiency

875 Nutrition is an integral aspect of good health and development that is related to stronger

876 immune systems, improved infant, safer pregnancy and childbirth, child and maternal health,

877 lower risk of non-communicable diseases (such as cardiovascular disease and diabetes), and

878 longevity (UNICEF, 2019). Today, the burden of malnutrition (such as micronutrient deficiency,

879 undernutrition, and overweight) especially in developing nations and the deadly Covid-19

880 pandemic is ravaging most part of the world. Given this, the food system has been greatly

881 explored to assess the potential role of bioactive compounds such as vitamins, in the fight against

882 malnutrition and Covid-19 (Jovic et al., 2020; Galanakis, 2020). In addition, various attempts

883 through nutrigenomics have been made with an emphasis on how different foods and their

884 components can interact with specific genes to yield health benefits such as the reduced risk of

885 neurodegenerative/metabolic/autoimmune diseases, and some cancers (Sikalidis, 2018). This can

886 be achieved by developing a personalized diet as a therapeutic approach to delaying and

887 preventing the onset of disease and ensure optimal maintenance of human health (Ronteltap, van

888 Trijp, Berezowska, \& Goossens, 2013; Neeha \& Kinth, 2013).

889 Besides its role against micronutrient deficiency (malnutrition), the consumption of foods

890 rich in vitamins has also been shown to boost the immune system to help fight off viruses (Naik,

891 Thakare \& Joshi, 2010; Gibson et al., 2012). This provided insights for several ongoing studies

892 on the use of food bioactive ingredients for the support of the human immune system against

893 infectious disease like Covid-19 (Galanakis, 2020). Specifically to viral infectious diseases, Jovic

894 et al., (2020) highlighted the potential role of vitamins A and $\mathrm{E}$ in the fight against Covid-19

895 through their antioxidant effect, enhancing natural barriers, immunomodulation, and local

896 paracrine signalling. Studies have also shown the beneficial role of vitamins $C$ and D either

897 through food or dietary supplements in the fight against Covid-19 (Dehghani-Samani, Kamali, \&

898 Hoseinzadeh-Chahkandak). For instance, it is well recognized that vitamin $\mathrm{C}$ is an essential

899 micronutrient needed for the development and repair of all body tissues, play a protective role

900 given its antioxidant effect, supports the immune function (Carr \& Maggini, 2017), and also

901 limits the responsiveness of lower respiratory tract to infection, under certain conditions (Hemila,

902 1997; Galanakis, 2020). 

support the human immune system against Covid-19 (Shakoor et al., 2021). In this new era of a pandemic, it is predicted that consumers will greatly go for immune-boosting products soon. This corroborates the findings of a survey that almost one in five consumers mentioned immune system support as the main reason for buying a healthy product (Avis, 2021).

\section{Food-sourced Vitamins and Dietary Supplements: Striking a Balance?}

Prior to the pandemic era, the use of dietary supplement has significantly increased over

910 the decades especially in developed nations, contributing to the nutrient intake in the population

911 (Lentjes, 2019). Originally, the ultimate goal of dietary/food/nutritional supplement is to act as a

912 vehicle for delivering nutrients that may not be consumed in adequate amounts. Dietary

913 supplements are usually micronutrients in the form of vitamins, minerals, and/or their

914 combinations with other substances prepared in the form of capsules, liquid, pills, tablets, etc.

915 and administered during nutrient deficiency situations (Mensink et al., 2013).

916 To reiterate, urbanization and some sort of modern dietary pattern aimed at boosting the

917 immune system and staying healthy could be the driving force behind the increased use of

918 dietary supplements (Lentjes, 2019). Dietary supplements are known to contain isolated nutrients

919 in high concentration which is capable of increasing the total nutrient intake by raising the

920 concentrations of the respective nutrients specifically vitamins, in blood plasma or serum

921 (Lentjes, 2019). This unhealthy lifestyle associated with nutritional excesses can cause series of

922 lifestyle-induced diseases such as diabetes, stroke, heart disease, obesity, etc. (Minich \& Bland,

923 2013). For example, high total nutrient intake of retinol $(\approx 2500 \mu \mathrm{g} /$ day $)$ in combination with

924 total nutrient intake of vitamin D $(<11 \mu \mathrm{g} /$ day $)$ has been linked with fractures in post-

925 menopausal women (Caire-Juvera et al., 2009).

926 Notably, dietary supplements cannot replace a balanced healthy diet because a diet

927 containing, for instance, whole grains, sufficient protein, healthy fats, fruits and vegetables can

928 be enough to meet the daily adequate vitamin intake needed for good health (FAO, 2001;

929 Kearney, 2017; Shao et al., 2017). However, vitamins are only required in certain amounts ( $\mu \mathrm{g}$

930 or $\mathrm{mg}$ ) and therefore higher amounts of some vitamins through supplementation could contribute

931 to increased nutrient intake, thereby causing harm (FAO/WHO, 2004; Molnar \& Gair, 2015).

932 Although dietary supplements are used to augment dietary gaps especially during

933 nutritional/micronutrient deficiency, studies have shown that nutrients from food are most 
934 important (Shenkin, 2006; Anonymous, 2021c). Table 7 shows the usual amount of vitamin

935 intake from various foods and the prevalence of potential dietary supplementation.

936 Food (fresh or processed) is composed of nutrients such as vitamins, minerals,

937 polyphenols, etc. necessary for the promotion of good health (Skerrett \& Willet, 2010).

938 According to Chen et al., (2019), adequate nutrient intake from food sources significantly

939 reduced all-cause of cardiovascular disease (CVD) mortality, but the lower risk of death

940 disappeared when the same nutrients were taken in the form of dietary supplements. This

941 corroborates the findings that supplement use has been associated with mortality (Mursu et al.,

942 2011). Furthermore, the study also showed that a lower risk of death was associated with

943 adequate nutrient intakes of vitamin $\mathrm{K}$ and magnesium, only when these nutrients were sourced

944 from food, but the lower death risk was lost when they were consumed as supplements (Chen et

945 al., 2019). In addition, lower risk of death from CVD associated with adequate intakes of

946 vitamins A, K and zinc were also reported, provided that nutrients were sourced from foods and

947 the lower death risk was lost when nutrients were consumed as supplements (Chen et al., 2019;

948 Upham, 2019). This corroborates the findings that nutrients are most potent when they are

949 obtained from food (Magee, 2010; Anon., 2015d; Chakrabarti, Guha \& Majumder, 2018; Khoo,

$950 \mathrm{Ng}$, Yap, Goh \& Yim, 2019). The findings of this research suggest that individuals and

951 population groups without any nutritional deficiency may benefit when vitamins and other

952 nutrients are obtained from a healthy balanced diet, of which same benefits may be lost if those

953 nutrients are obtained from dietary supplements. This implies that dietary supplement cannot be

954 a replacement for a healthy diet and should not be a frequent part of the modern lifestyle of

955 personalized diet.

956

957

958

959

960

961

962

963

964

\section{CONCLUDING REMARKS AND FUTURE PROSPECTS}

We have, in this perspective review, revisited food-sourced vitamins, and thrown more light to their classification, metabolic functions, absorption, transport, deficiencies, and toxicities. Adding its importance as micronutrients, vitamins have to be provided in the required amounts for vital physiological functions and biochemical processes crucial to human living. How the physical and chemical properties of vitamins would influence the absorption of vitamins, vitamin transport, cellular uptake, and excretion, were also enumerated in this paper. As no single food source contains all the vitamins, a balanced healthy diet consumed from a variety of foods of plant and animal origin would help meet what the body needs. Besides

Peer) reviewing PDF | (2021:03:59124:1:1:NEW 28 Jun 2021) 
965 performing a physiological function as an antioxidant, co-enzyme, hormone, and electron 966 donor/acceptor (cofactors), the mode of vitamin absorption (simple, passive, facilitated, and 967 carrier-mediated diffusion), a vehicle for vitamin transport (free in plasma, erythrocyte carried, 968 lipoproteins, specific binding, and non-specific binding proteins), and mode of cellular uptake

969

970

971

972

973

974

975

976

977

978

979

980

981

982

983

984

985

986

987

988

989

990

991

992

993

994

995 equally varies and depends on their associated chemical properties.

All vitamin absorption takes place in the small intestine. As water-soluble vitamins diffuse across the brush border membrane of intestinal mucosa into the bloodstream to the target cells and tissues, the fat-soluble vitamins require the help of bile acids to diffuse through the intestinal mucosa to the lymphatic system after being packaged as mixed micelles and transported by carrier-dependent proteins to peripheral tissues and liver. Besides the failure of ingesting vitamin-rich foods, vitamin deficiency can arise from impaired intestinal vitamin absorption owed to intestinal disease, genetic disorders in transport, excessive alcohol consumption, and interaction with drugs. Vitamins can also interact with each other, other food components, and certain factors such as $\mathrm{pH}$, temperature, and light, to exhibit different degrees of absorption efficiency as well as partial or complete degradation. Additionally, the frequent and unchecked intake of vitamin supplements can induce vitamin toxicity, especially from fatsoluble types.

For the ultimate goal of safeguarding consumers' health, obtaining vitamins naturally from the diet should be paramount to the intake from a vitamin supplement. Using micronutrient supplements to solve an unhealthy dietary pattern is a parochial approach to solving an unhealthy lifestyle. Therefore as the use of dietary supplement continues to increase, monitoring their contribution to diet, health, and disease is very crucial. The right amounts of vitamins must be contained in our daily meals to address the problem of micronutrient deficiency caused by nutritional insecurity especially in developing nations, as well as to support and maintain the sustainability of the human immune system against infections and health crises.

This perspective review has provided a foundational insight that can help future studies to dig deeper into understanding the intricacies that underpin how fat- and water-soluble vitamins interact with macronutrients within the food component matrix, and its influence on the absorption efficiency, transport, and cellular uptake. The direction of future studies should focus on developing technologies and processes that will make staple foods and frequently consumed commercial food products (for example, instant noodles, pasta, and some confectionery goods) 
996 as carriers and delivery system for vitamins especially the most common global deficient

997 vitamins. This can be achieved by making vitamins as bioactive agents in commercial food

998 products, such that vitamins maintain their effectiveness in an active form when it reaches the

999 active site after ingestion, without variation in their efficacy.

1000 CONFLICT OF INTEREST

1001 Charles Odilichukwu R. Okpala is an Academic Editor for PeerJ.

1002 FUNDING

1003 Authors CEO, VSI, JSC, and AOA acknowledge financial support from the Chinese

1004 Scholarship Council (CSC) and South China University of Technology, Guangzhou, Guangdong,

1005 China. Authors MK, JN, and CORO acknowledge financial support from the Wroclaw

1006 University of Environmental and Life Sciences, Wroclaw, Poland. This publication was financed

1007 by the project UPWR 2.0: international and interdisciplinary programme of development of

1008 Wrocław University of Environmental and Life Sciences, co-financed by the European Social

1009 Fund under the Operational Program Knowledge Education Development, under contract No.

1010 POWR.03.05.00-00-Z062/18 of June 4, 2019. There was no additional funding received for this

1011 study.

1012 REFERENCES

1013 Albahrani, A.A., Greaves, R.F. 2016. Fat-soluble vitamins: Clinical indications and current

1014 challenges for chromatographic measurement. Clin. Biochem. Rev. 37(1): 27-47.

1015 Anonymous. 2015. Should you get your nutrients from food or from supplements? In: Staying

1016 Healthy. Harvard Medical School, Harvard Health Publishing.

1017

1018

1019

1020

1021

1022

1023

1024

1025

1026

1027

1028

1029 https://www.health.harvard.edu/staying-healthy/should-you-get-your-nutrients-fromfood-or-from-supplements (accessed 12 June, 2021).

Anonymous. 2021a. Vitamin B7 (Biotin). https://nuts.com/healthy-eating/vitamin-b7 (accessed 25 February 2021).

Anonymous. 2021b. Vitamin B12 overdose, In: Vitamin B12 \& Health. Association for the promotion of holistic health. https://www.b12-vitamin.com/overdose/ (accessed 25 February 2021).

Anonymous 2021c. Nutrition and healthy eating. In: Healthy lifestyle. https://www.mayoclinic.org/healthy-lifestyle/nutrition-and-healthy-eating/indepth/supplements/art-20044894 (accessed 10 June, 2021).

Allen, L.H., Miller, J.W., de Groot, L., Rosenberg, I.H., Smith, D.A. Raiten, D.J. 2018. Biomarkers of Nutrition for Development (BOND): Vitamin B-12 Review. Journal of Nutrition, 148(suppl): 1995S-2027S. https://doi.org/10.1093/jn/nxy201 
1030 Alshahrani F, Aljohani N. 2013. Vitamin D: Deficiency, Sufficiency, and Toxicity. Nutrients

1031

1032

1033

1034

1035

1036

1037

1038

1039

1040

1041

1042

1043

1044

1045

1046

1047

1048

1049

1050

1051

1052

1053

1054

1055

1056

1057

1058

1059

1060

1061

1062

1063

1064

1065

1066

1067

1068

1069 5:3605-3616; doi:10.3390/nu5093605

Avis, E. 2021. Consumers are looking for immunity boosting ingredients. The coronavirus accelerated the trend toward food that supports the immune system. https://www.foodprocessing.com/articles/2021/immunity-boosting-ingredients/ (accessed 12 June 2021).

Avrutin A. 2020. All about vitamins. Davidson Institute of Science Education. https://davidson.weizmann.ac.il/en/online/maagarmada/all-about-vitamins (accessed 3 December 2020).

Axmann, M., Strobl, W.M., Plochberger, B., Stangl, H. 2019. Cholesterol transfer at the plasma membrane. Atherosclerosis, 290: 111-117. http://dx.doi.org/10.1016/j.atherosclerosis.2019.09.022

Bailey LB, da Silva V, West AA, Caudill MA. 2014. Folate. In: Zempleni J, Sutties JW, Gregory JF, Stover PJ, editors. Handbook of Vitamins. 5th ed. New York, USA: CRC Press, Taylor \& Francis Group.

Bailey, L.B., Stover, P.J., McNulty, H., Fenech, M.F., Gregory, J.F., Mills, J.L., Pfeiffer, C.M., Fazili, Z., Zhang, M., Ueland, P.M., Molloy, A.M., Caudill, M.A., Shane, B., Berry, R.J., Bailey, R.L., Hausman, D.B., Raghavan, R., Raiten, D.J. 2015. Biomarkers of Nutrition for Development—Folate Review. Journal of Nutrition, 145(7): 1636S1680S. doi:10.3945/jn.114.206599.

Ball G.F.M. 2004. Vitamins. Their role in human body. Oxford, UK: Blackwell Publishing. Bates CJ. 1997. Bioavailability of riboflavin. Eur. J. Clin. Nutr., 51: S38-S42.

Bender DA. 2003. Nutritional Biochemistry of the Vitamins. $2^{\text {nd }}$ ed. Cambridge, UK: Cambridge University Press.

Bhagavan, N.V., Ha, C.-E. 2015. Vitamin Metabolism. In: Bhagavan, N.V., Ha, C.-E (eds.) Essentials of Medical Biochemistry (Second Edition). Amsterdam: Academic Press. Pp. 683-699. https://doi.org/10.1016/B978-0-12-416687-5.00036-1

Blanco, A., Blanco, G. 2017. Vitamains. In: Blanco, A., Blanco, G. (eds.). Medical Chem istry. Amsterdam, Netherland: Academic Press, Elsevier BV. Pp. 645-687. https://doi.org/10.1016/B978-0-12-803550-4.00027-6

Bowen, R. 2007. Endocrine control of calcium and phosphate homeostasis. http://www.vivo.colostate.edu/hbooks/pathphys/endocrine/thyroid/calcium.html (accessed 7 June 2021.

Bowen R. (2018) Absorption of vitamins. https://www.vivo.colostate.edu/hbooks/pathphys/digestion/smallgut/absorb_vitamins.htm 1 (accessed 20 December 2020].

Borel, P. 2009. Nutrigenetic effect on instetinal absorption of fat-soluble microconstituents (Vitamins A, E, D and K, Carotenoids and Phytosterols). In: Global Issues in Food Science and Technology. Amsterdam, Netherland: Academic Press, Elsevier BV. Pp. 3142. https://doi.org/10.1016/B978-0-12-374124-0.00003-X 
1070 Bouillon, R., Schuit, F., Antonio, L., Rastinejad, F. 2020. Vitamin D binding protein: A his

1071

1072

1073

1074

1075

1076

1077

1078

1079

1080

1081

1082

1083

1084

1085

1086

1087

1088

1089

1090

1091

1092

1093

1094

1095

1096

1097

1098

1099

1100

1101

1102

1103

1104

1105

1106

1107

1108

1109

1110 toric overview. Front. Endocrinol. 10: 910. https://doi.org/10.3389/fendo.2019.00910.

Brito A., Mujica-Coopman MF., Lopez de Romana D., Cori H., Allen LH. 2015. Folate and vitamin B12 status in Latin America and the Caribbean: an update. Food Nutr. Bull. 35(2Suppl): S109-18.

Brown, M. J., Ferruzzi, M. G., Nguyen, M. L., Cooper, D. A., Eldridge, A. L., Schwartz, S. J., and White, W. S. 2004. Am. J. Clin. Nutr. 80, 396-403

Buehler BA. 2011. Vitamin B2: Riboflavin. Journal of Evidence-Based Complementary \& Alternative Medicine. 16(2): 88-90, DOI: 10.1177/1533210110392943

Caire-Juvera, G., Ritenbaugh, C., Wactawski-Wende, J., Snetselaar, L.G., Chen, Z. 2009. Vitamin A and retinol intakes and the risk of fractures among participants of the Women's Health Initiative Observational Study. Am J Clin Nutr 89(1): 323-330. doi: 10.3945/ajen.2008.26451.

Carling RS, Turner C. 2018. Methods for assessment of biotin (Vitamin B7). In: Laboratory Assessment of Vitamin Status. Academic Press Elsevier. Pp. 193-217. https://doi.org/10.1016/C2016-0-04426-1

Carr, A.C.; Maggini, S. 2017. Vitamin C and immune function. Nutrients, 9: 1211.

Carr, A.C., Rowe, S. 2020. Factors affecting vitamin C status and prevalence of deficiency: A global health perspective. Nutrients, 12(7): 1963. https://dx.doi.org/10.3390\%2Fnu12071963

Carreiro, A.L., Buhman, K.K. 2019. Absorption of dietary fat and its metabolism in enterocytes. In: The Molecular Nutrition of Fats. Amsterdam: Academic Press, Elseivier, BV. Pp. 33-48.

Caswell, J.A., Yaktine, A.L. 2013. Supplemental Nutrition Assistance Program. In: Caswell, J.A., Yaktine, A.L. (eds.) Examining the Evidence to Define Benefit Adequacy. Washington (DC), USA: The National Academies Press. DOI: 10.17226/13485

Combs, G.F. 2008. The Vitamins. In: Fundamental Aspects in Nutrition and Health, $3^{\text {rd }}$ ed. California: USA: Elsevier Academic Press.

Chakrabarti, S., Guha, S., Majumder, K. 2018. Food-derived bioactive peptides in human health: Challenges and Opportunities. Nutrients 10(11): 1738. https://doi.org/10.3390/nu10111738

Charen, E., Harbord, N. 2020. Toxicity of Herbs, Vitamins, and Supplements. Advances in Chronic Kidney Disease 27(1): 67-71.

Chen, Y., Michalak, M., Agellon, L.B. 2018. Importance of nutrients and nutrient metabo lism on human health. Yale J. Biol. Med. 91(2): 95-103.

Christian, P., West, K.P. 1998. Interactions between zinc and vitamin A: an update ${ }^{1-4} . A m$. J. Clin. Nutr. 68(suppl): 435S-41S.

Christie, W.W. 2021. Plasma Lipoproteins. In: The Lipid Web. https://www.lipidmaps.org/resources/lipidweb/lipidweb_html/lipids/simple/lipoprot/inde x.htm (accessed 14 June, 2021).

Chung M, Balk EM, Brendel M, Ip S, Lau J, Lee J, Lichtenstein A, Patel K, Raman G, 
1111

1112

1113

1114

1115

1116

1117

1118

1119

1120

1121

1122

1123

1124

1125

1126

1127

1128

1129

1130

1131

1132

1133

1134

1135

1136

1137

1138

1139

1140

1141

1142

1143

1144

1145

1146

1147

1148

1149

1150

1151

Tatsioni A, Terasawa T. 2009. Vitamin D and calcium: a systematic review of health outcomes. Evidence report/technology assessment, (183):1-420.

Cooper, G.M. 2000. The Central Role of Enzymes as Biological Catalysts. In: The Cell: A Molecular Approach. 2nd edition. Sunderland (MA): Sinauer Associates.

Dakshinamurti S, Dakshinamurti K. 2014. Vitamin B6. In: Zempleni J, Sutties JW, Gregory JF, Dakshinamurti K. 2005. Biotin — a regulator of gene expression. J. Nutr. Biochem., 16: 419-423.

Davidson RA. 1984. Complications of megavitamin therapy. Sousk. Med. J. 77:200-3.

Decker KF. 1993. Biosynthesis and function of enzymes with covalently bound flavin. Annu. Rev. Nutr., 13: 17-41.

Dehghani-Samani, A., Kamali, M., Hoseinzadeh-Chahkandak, F. 2020. The role of vitamins on the prevention and/or treatment of COVID-19 infection; a systematic review. Mod. Care J. 17(3): e104740

Delaney KZ, Barke L. 2017. More about vitamins. In: Fundamentals of health and physical activity. https://opentextbooks.concordia.ca/fundamentalsofhealthandphysicalactivity/chapter/1-83-about-vitamins/ (accessed 8 December 2020).

DeLaval 2007. Vitamins and minerals functioning as antioxidants with supplementation considerations. http://www.milkproduction.com/Library/Scientificarticles/Nutrition/Vitamins-and-minerals/ (accessed 5 June 2021).

DellaPenna D. 2005. Progress in dissection and manipulation of vitamin E synthesis. Trends in Plant Science, 10(12): 574-579.

de La Rochette,A., Silva, E., Birlouez-Aragon, I., Mancini, M., Edwards, A.-M., Morliere, P. 2000. Riboflavin photodegradation and photosensitizing effects are highly dependent on oxygen and ascorbate concentration. Photochemistry and Photobiology, 72(6): 815820. https://doi.org/10.1562/0031-8655(2000)072\%3C0815:RPAPEA\%3E2.0.CO;2

DeLuca, H.F. 1986. The metabolism and functions of vitamin D. Adv. Exp. Med. Biol. 196: 361-375.

de Ridder, D., Kroese, F., Evers, C., Adriaanse, M., Gillebaart, M. 2017. Healthy diet: Health impact, prevalence, correlates, and interventions. Psychology \& Health 32(8): 907-941. https://doi.org/10.1080/08870446.2017.1316849

Djadjo S. 2021. Niacin. https://www.statpearls.com/ArticleLibrary/viewarticle/38460\# (accessed 19 May 2021).

Drake, V.J. 2017. Micronutrient inadequacies in the US population: an Overview. https://pi.oregonstate.edu/mic/micronutrient-inadequacies/overview (accessed 10 June 2021).

Drugbank 2021. Menadione. https://go.drugbank.com/drugs/DB00170. (accessed 2 July 2021).

El-Kattan, A., Varma, M. 2012. Oral absorption, intestinal metabolism and human oral bioavailability. In: Paxton, J. (ed.) Topics on Drug Metabolism. IntechOpen. DOI: $10.5772 / 31087$

PeerJ reviewing PDF | (2021:03:59124:1:1:NEW 28 Jun 2021) 
1152 Evans, C.D.H., Lacey, J.H. 1986. Toxicity of vitamins: complications of a health movement.

1153

1154

1155

1156

1157

1158

1159

1160

1161

1162

1163

1164

1165

1166

1167

1168

1169

1170

1171

1172

1173

1174

1175

1176

1177

1178

1179

1180

1181

1182

1183

1184

1185

1186

1187

1188

1189

British Med J., 292(6519): 509-510. doi: 10.1136/bmj.292.6519.509

Ernst, L.N.M. 2016. Possible kidney clearance role and time-course of the effects in phosphate homeostasis. Published Thesis. http://dspace.uvic.cat/bitstream/handle/10854/4699/trealu_a2016_monta\%c3\%b1a_lena fgf 23 possible.pdf? $\mathrm{cv}=1 \&$ is Allowed $=\mathrm{y} \&$ sequence $=1$ (accessed 6 June 2021).

FAO. 2001. FAO/WHO expert consultaion on human vitamin and mineral requirement. Report of a joint FAO/WHO expert consultation Bangkok, Thailand.

FAO/WHO. 2004. Vitamin and Mineral requirements in human nutrition: Report of a joint FAO/WHO expert consultation, Bangkok, Thailand, 21 -30 September 1998.

FAO/WHO. 2019. Sustainable healthy diets. Guiding principles. Rome. http://www.fao.org/3/ca6640en/ca6640en.pdf (accessed 14 June, 2021).

Feingold, K.R. 2000. Introduction to Lipids and Lipoproteins. In: Feingold KR, Anawalt B, Boyce A, Chrousos G, de Herder WW, Dhatariya K, Dungan K, Grossman A, Hershman JM, Hofland J, Kalra S, Kaltsas G, Koch C, Kopp P, Korbonits M, Kovacs CS, Kuohung W, Laferrère B, McGee EA, McLachlan R, Morley JE, New M, Purnell J, Sahay R, Singer F, Stratakis CA, Trence DL, Wilson DP (eds.) South Dartmouth (MA), USA: MDText.com Inc.

Florentin, M., Liberopoulos, E.N., Kei, A., Mikhailidis, D.P., Elisaf, M.S. 2011. Pleiotropic effects of nicotinic acid: beyond high density lipoprotein cholesterol elevation. Curr. Vasc. Pharmacol. 9(4): 385-400.

Fricker, R.A., Green, E.L., Jenkins, S.I., Griffin, S.M. 2018. The influence of Nicotinamide on health and disease in the Central Nervous System. Int. J. Tryptophan Res. 11: 1178646918776658 .

Galanakis, C.M. 2020. The food systems in the era of the Coronavirus (COVID-19) Pandemic Crisis. Foods, 9: 523. doi:10.3390/foods9040523

Gao, Z., Fang, Y., Cao, Y. Liao, H. Nishinari, K., Philli, G.O. 2016. Hydrocolloid-Food component interactions. Food Hydrocolloid. Doi: 10.1016/j.foodhyd.2016.08.042

Gasperi, V., Sibilano, M., Savine, I., Catani, M.V. 2019. Niacin in the central Nervous System: An Update of Biological Aspects and Clinical Applications. Int. J. Mol. Sci. 20(4): 974.

Gibson, A.; Edgar, J.D.; Neville, C.E.; Gilchrist, S.E.C.M.; McKinley, M.C.; Patterson, C.C.; Young, I.S.; Woodside, J.V. 2012. Effect of fruit and vegetable consumption on immune function in older people: A randomized controlled trial. Am. J. Clin. Nutr. 96: 14291436.

Gil A, Plaza-Diaz J, Mesa MD. 2018. Vitamin D: Classic and Novel Actions. Annals of Nutrition and Metabolism 72(2): 87-95.

Godoy, H.T., Amaya-Farfan, J., Rodriguez-Amaya, D.B. 2021. Degradation of vitamins. In:

PeerJ reviewing PDF | (2021:03:59124:1:1:NEW 28 Jun 2021) 
1190

1191

1192

1193

1194

1195

1196

1197

1198

1199

1200

1201

1202

1203

1204

1205

1206

1207

1208

1209

1210

1211

1212

1213

1214

1215

1216

1217

1218

1219

1220

1221

1222

1223

1224

1225

1226

1227

1228

Chemical Changes During Processing and Storage of Foods. Amsterdam, Netherland: Academic Press, Elsevier BV. Pp. 329-383. https://doi.org/10.1016/B978-0-12-8173800.00008-7

Goncalves A, Roi S, Nowicki M, Dhaussy A, Huertas A, Amiot M-J, Reboul E. 2015. Fatsoluble vitamin intestinal absorption: Absorption sites in the intestine and interactions for absorption. Food Chemistry, 172: 155-160.

Gorbach, S.L. 1996. Microbiology of the gastrointestinal tract. In: Baron S. (eds) Medical Microbiology, $4^{\text {th }}$ edition. Galveston (TX): University of Texas Medical Branch at Galveston. Chapter 95.

Griffiths, J.K. 2013. Vitamin Deficiencies. In: Magill, A.J., Hill, D.R., Solomon, T., Ryan, E.T. (eds.) Hunter's Tropical Medicine and Emerging Infectious Disease ( $9^{\text {th }}$ edition). Amsterdam, Netherland: Elsevier BV. Pp. 997-1002. https://doi.org/10.1016/B978-14160-4390-4.00139-9

Harvard Medical School. 2020. Listing of vitamins. In: Institute of Medicine guidelines on vitamin recommendations. Harvard Health Publishing. https://www.health.harvard.edu/staying-healthy/listing_of vitamins (accessed 10 June 2021).

Halsted, C.H. 2003. Absorption of water-soluble vitamins. Curr. Opin. Gastroenterol. 19(2): 113-117. https://doi.org/10.1097/00001574-200303000-00003

Hemilä, H. 1997. Vitamin C intake and susceptibility to pneumonia. Pediatr. Infect. Dis. J. 16: 836-837.

Holick MF. 2004. Sunlight and vitamin D for bone health and prevention of autoimmune diseases, cancers, and cardiovascular disease. Am J Clin Nutr., 80(suppl):1678S-1688S.

Hs CY, Wang PW, Alalaiwe A, Lin ZC, Fang JY. 2019. Use of lipid nanocarriers to improve oral delivery of vitamin. Nutrients, 11(68): 1-30.

Hill MJ. 1997. Intestinal flora and endogenous vitamins synthesis. European Journal of Cancer Prevention 6(1): 43-45.

Ilkhani F., Hosseini B., Saedisomeolia A. 2016. Niacin and oxidative stress: A mini-Review. J. Nutr. Med. Diet Care 2(1): 014.

Institute of Medicine. 2000. Dietary Reference Intakes for Vitamin C, Vitamin E, Selenium, and Carotenoids. Washington DC, USA: The National Academies Press. Pp. 186-283. https://doi.org/10.17226/9810.

Iqbal J, Hussain MM.2009. Intestinal lipid absorption. Am J Physiol Endocrinol Metab., 296: E1183-E1194.

Jan YH., Richardson JR., Baker AA., Mishin V., Heck DE., Laskin DL., Laskin JD. 2015. Vitamin K3 (Menadione) redox cycling inhibits cytochrome P450-mediated metabolism and inhibits parathion intoxication. Toxicol Appl Pharmacol. 288(1): 114-20 DOI: 10.1016/j.taap.2015.07.023

Johnston CS, Steinberg FM, Rucker RB. 2014. Ascorbic acid. In: Zempleni J, Sutties JW, 
1229

1230

1231

1232

1233

1234

1235

1236

1237

1238

1239

1240

1241

1242

1243

1244

1245

1246

1247

1248

1249

1250

1251

1252

1253

1254

1255

1256

1257

1258

1259

1260

1261

1262

1263

1264

1265

1266

1267

1268

Gregory JF, Stover PJ, editors. Handbook of Vitamins. 5th ed. New York, USA: CRC Press, Taylor \& Francis Group.

Johnson LE. 2020. Vitamin Deficiency, Dependency and Toxicity. In: Nutritional Disorders. https://www.msdmanuals.com/professional/nutritional-disorders/vitamin-deficiencydependency-and-toxicity/vitamin-a-deficiency (accessed 20 February 2021).

Jong N. de, Ocké MC, Branderhorst HAC., Friele R. 2003. Demographic and lifestyle characteristics of functional food consumers and dietary supplement users. British Journal of Nutrition, 89(2): 273-281.

Jovic, T.H., Ali, S.R., Ibrahim, N., Hessop, Z.M., Tarassoli, S.P., Dobbs, T.D., Holford, P., Thornton, C.A., Whitaker, I.S. 2020. Could vitamins help in the fight against COVID-19? Nutrients, 12: 2550. doi:10.3390/nu12092550

Kearney, J. 2010. Food consumption trends and drivers. Philos. Trans. R. Soc. Lond. B. Biol. Sci. 365(1554): 2793-2807. https://dx.doi.org/10.1098\%2Frstb.2010.0149

Kei, A., Liberopoulos, E.N., Elisaf, M.S. 2011. What restricts the clinical use of nicotinic acid? Curr. Vasc. Pharmacol. 9(4): 521-530.

Khammissa, R.A.G., Fourie, J., Motswaledi, M.H., Ballyram, R., Lemmer, J., Feller, L. 2018. The biological activities of vitamin $\mathrm{D}$ and its receptor in relation to calcium and bone homeostasis, cancer, immune and cardiovascular systems, skin biology, and oral health. BioMed Research International. Article ID 9276380 https://doi.org/10.1155/2018/9276380

Khoo, H.E., Ng, S.H., Yap, W.-S., Goh, H.J.H., Yim, H.S. 2019. Nutrients for prevention of macular degeneration and eye-related diseases. Nutrients 8(4): 85. https://doi.org/10.3390/antiox8040085

Kumar, A., Palfrey, H.A., Pathak, R., Kadowitz, P.J., Gettys, T.W., Murthy, S.N. 2017. The metabolism and significance of homocysteine in nutrition and health. Nutr. Metab. (Lond) 14:78. https://dx.doi.org/10.1186\%2Fs12986-017-0233-z

Kumanyika, S., Oria, M.P. 2017. Guiding Principles for Developing Dietary Reference Intakes Based on Chronic Disease. In: Kumanyika, S., Oria, M.P. (eds.) Consensus Study Report. Washington DC: The National Academies Press. http://nap.edu/24828 (accessed 28 January 2021).

Lattimer, J.M. Haub, M.D. 2010. Effects of dietary fiber and its components on metabolic health. Nutrients, 2(12): 1266-1289. https://dx.doi.org/10.3390\%2Fnu2121266

Leitzmann, C. n.d. Adequate diet of essential nutrients for healthy people. In: The Food, Agriculture, Forestry and Fisheries in Human Nutrition - Vol. IV. https://www.eolss.net/sample-chapters/c10/E5-01A-06-01.pdf (accessed 12 June 2021).

Li, N., Zhao, G., Wu, W., Zhang, M., Liu, W., Chen, Q., Wang, X. 2020. The efficacy and safety of vitamin $\mathrm{C}$ for iron supplementation in Adult patients with iron deficiency anemia. JAMA Network Open, 3(11): e2023644. http://doi.org/10.1001/jamanetworkopen.2020.23644

Magee, E. 2010. 10 Nutrient-Rich Super Foods. 
1269

1270

1271

1272

1273

1274

1275

1276

1277

1278

1279

1280

1281

1282

1283

1284

1285

1286

1287

1288

1289

1290

1291

1292

1293

1294

1295

1296

1297

1298

1299

1300

1301

1302

1303

1304

1305

1306

1307

1308

1309

https://www.webmd.com/food-recipes/features/10-super-foods (accessed 10 June, 2021).

Mahmood, L. 2014. The metabolic processes of folic acid and vitamin B12 deficiency. $J$. Health Res. Rev 1: 5-9. DOI: 10.4103/2394-2010.143318

Martini LA, Verly Jr E, Marchioni DM, Fisberg RM. 2013. Prevalence and correlates of calcium and vitamin D status adequacy in adolescents, adults, and elderly from the Health Survey—São Paulo. Nutrition., 29(6):845-850.

McDowell, L.R., Wilkinson, N., Madison, R., Felix, T. 2007. Vitamins and minerals functioning as antioxidants with supplementation considerations. Florida Ruminant Nutrition Symposium. Gainesville, FL: Best Western Germany Gateway Grand. January 30-31.

McNamara, K., Wood, E. 2019. Food taboos, health beliefs, and gender: understanding household food choice and nutrition in rural Tajikistan. Journal of Health, Population and Nutrition 38(17). https://doi.org/10.1186/s41043-019-0170-8

Mensink GB, Fletcher R, Gurinovic M, Huybrechts I, Lafay L, Serra-Majem L, Szponar L, Tetens I, Verkaik-Kloosterman J, Baka A, Stephen AM. 2013. Mapping low intake of micronutrients across Europe. British Journal of Nutrition 14:1-19.

Meydani, M., Martin, K.R. 2001. Intestinal Absorption of Fat-Soluble Vitamins. In: Mans bach C.M., Tso P., Kuksis A. (eds). Intestinal Lipid Metabolism. Boston, MA; Springer. https://doi.org/10.1007/978-1-4615-1195-3_20.

Minichi, D.M., Bland, J.S. 2013. Personalized lifestyle medicine: Relevance for nutrition and lifestyle recommendations. Scientific World Journal 2013: 129841. https://dx.doi.org/10.1155\%2F2013\%2F129841

Molnar, C., Gair, J. 2015. Nutrition and Energy Production. In: Concepts of Biology - $1^{\text {st }}$ Canadian Edition. Vancouver, Canada: BBcampus Publishers. https://opentextbc.ca/biology/chapter/15-2-nutrition-and-energy-production/ (accessed 14 June, 2021).

Muller, M., Canfora, E.E., B;aak, E.E. 2018. Gastrointestinal transit time, glucose homeostat sis and metabolic health: Modulation by dietary fibers. Nutrients, 10(2): 275. https://dx.doi.org/10.3390\%2Fnu10030275

Mursu J, Robien K, Harnack LJ, Park K, Jacobs DR Jr. 2011. Dietary supplements and mortality rate in older women: the Iowa Women's Health Study. Arch Intern Med 171(18): 1625-1633. doi: 10.1001/archinternmed.2011.445.

Naik, S.R.; Thakare, V.N.; Joshi, F.P. 2010. Functional foods and herbs as potential immunoadjuvants and medicines in maintaining healthy immune system: A commentary. J. Complement. Integr. Med. 7: 1

Nair R., Maseeh A. 2012. Vitamin D: The "sunshine" vitamin. Journal of Pharmacology and Pharmacotherapeutics 3(2): 118-126.

Neeha VS, Kinth P. 2013. Nutrigenomics research: a review. J Food Sci Technol. 50(3):415428. doi:10.1007/s13197-012-0775-z.

Newman T. 2017. All you need to know about beta carotene. Available on http://www.medicalnewstoday.com/articles/2527581/ (accessed 2 October 2020). 
1310 Ottaway P.B. 1993. Stability of vitamins in food. In: Ottaway P.B. (eds) The Technology

1311

1312

1313

1314

1315

1316

1317

1318

1319

1320

1321

1322

1323

1324

1325

1326

1327

1328

1329

1330

1331

1332

1333

1334

1335

1336

1337

1338

1339

1340

1341

1342

1343

1344

1345

1346

1347

1348

1349

1350

of Vitamins in Food. Boston, MA: Springer https://doi.org/10.1007/978-1-4615-2131-0 5

Picincu, A. 2021. Vitamin B1 Overdose Symptoms, https://www.livestrong.com/article/367247-vitamin-b1-overdose-symptoms/ (accessed 24 February 2021.

Pinto JT, Rivlin RS. 2014. Riboflavin (Vitamin B2) In: Zempleni J, Sutties JW, Gregory JF, Stover PJ, editors. Handbook of Vitamins. 5th ed. New York, USA: CRC Press, Taylor \& Francis Group.

Puglisi, M. 2019. Dietary fat and sports performance. In: Nutrition and Enhanced Sports Performance, 2nd Edition. Amsterdam: Academic Press, Elseivier, BV. Pp. 555-569.

Reboul E. 2017. Vitamin E Bioavailability: Mechanisms of Intestinal Absorption in the spotlight. Antioxidants, 6(95): 1-11.

Reboul E, Borel P. 2011. Proteins involved in uptake, intracellular transport, and basolateral secretion of fat-soluble vitamins and carotenoids by mammalian enterocytes. Progress in Lipid Research, 50(4):388-402.

Riedl, J., Linseisen, J., Hoffmann, J., Wolfram, G. 1999. Some dietary fibers reduce the absorption of carotenoids in women. J. Nutr. 129(12): 2170-2176. DOI: 10.1093/jn/129.12.2170.

Rigby, S.H., Schwarz, K.B. 2001. Nutrition and Liver Disease. In: Nutrition in the Prevention and Treatment of Disease. Amsterdam, Netherland: Academic Press, Elsevier BV. Pp. 601-613. https://doi.org/10.1016/B978-012193155-1/50041-6

Roodenburg, A. J., Leenen, R., van het Hof, K. H., Weststrate, J. A., Tilburg, L. B. 2000. Am. J. Clin. Nutr. 71, 1187-1193.

Ronteltap A, van Trijp H, Berezowska A, Goossens J. 2013. Nutrigenomics-based

personalised nutritional advice: in search of a business model? Genes Nutr. 8(2):153-163. doi:10.1007/s12263-012-0308-4.

Ross C, Harrison EH. 2014. Vitamin A: Nutritional Aspects of Retinoids and Carotenoids. In: Zempleni J, Sutties JW, Gregory JF, Stover PJ, (eds.) Handbook of Vitamins. 5th ed. New York, USA: CRC Press, Taylor \& Francis Group.

Ruiz, A.R. Overview of Malabsorption. In: Gastrointestinal disorders. https://www.msdmanuals.com/professional/gastrointestinal-disorders/malabsorptionsyndromes/overview-of-malabsorption (accessed 14 June, 2021).

Saba, A. Oridupa, O. 2012. Lipoproteins and Cardiovascular Diseases, Lipoproteins - Role in Health and Diseases, Sasa Frank and Gerhard Kostner, IntechOpen, DOI: 10.5772/48132. https://www.intechopen.com/books/lipoproteins-role-in-health-and-diseases/lipoproteinsand-cardiovascular-diseases (accessed 14 June, 2021).

Said HM. 2004 Recent advances in carrier-mediated intestinal absorption of water-soluble vitamins. Annu Rev Physiol.; 66:419-46.

Said HM. 2011. Intestinal absorption of water-soluble vitamins in health and disease. Biochem. J., 437(3): 357-372.

SAL. 2017. Sight and Life Publication. Vitamins and Minerals: a brief guide. 
1351

1352

1353

1354

1355

1356

1357

1358

1359

1360

1361

1362

1363

1364

1365

1366

1367

1368

1369

1370

1371

1372

1373

1374

1375

1376

1377

1378

1379

1380

1381

1382

1383

1384

1385

1386

1387

1388

1389

1390

http://sightandlife.org $>2017 / 03$ PDF (accessed 8 January 2021).

Sanders, R. (2002). Megavitamins may be useful treatment for many genetic diseases, or just good insurance to tune up body's metabolism. https://www.berkeley.edu/news/media/releases/2002/04/04 vitam1.html (accessed 13 June 2021).

Scott JM, Weir DG. 1994. Folate/vitamin B12 interrelationships. Essays in Biochemistry, 28:63-72.

Scheerger SB, Zempleni J. 2003. Expression of oncogenes depends on biotin in human small cell lung cancer cells NCI-H69. Int. J. Vit. Nutr. Res., 73: 461-467.

Schnellbaecher, A., Binder, D., Bellmaine, S., Zimmer, A. 2019. Vitamins in cell culture media: Stability and stabilization strategies. Biotechnol. Bioeng. 116(6): 1537-1555. https://dx.doi.org/10.1002\%2Fbit.26942

Scott KJ, Rodriquez AD. 2000. Pro-vitamin A carotenoid conversion factors: retinol equivalents, fact or fiction? Food Chemistry 69(2): 125-127.

Shao, A., Drewnowski, A., Willcox, D.C., Kramer, L., Lausted, C., Eggersdofer, M., Mathers, J., Bell, J.D., Randolph, R.K., Witkamp, R., Griffiths, J.C. 2017. Optimal nutrition and the ever-changing dietary landscape: a conference report. Eur. J. Nutr. 56(Suppl 1): 1-21. https://dx.doi.org/10.1007\%2Fs00394-017-1460-9

Shakoor, H., Feehan, J., Al Dhaheri, A.S., Ali, H.I., Platat, C., Ismail, L.C., Apostolopoulos, V., Stojanovska, L. 2021. Immune-boosting role of vitamins D, C, E, zinc, selenium and omega-3 fatty acids: Could they help against COVID-19? Maturitas, 143: 1-9.

Shane, B. 2008. Folate and vitamin B12 metabolism: Overview and interaction with ribofla vin, vitamin B6, and polymorphisms. Food and Nutrition Bulletin, 29(2): S5-S16.

Shane B. 2009. Folate chemistry and metabolism. In: Bailey LB, editor. Folate in Health and Disease. 2nd ed. Boca Raton, FL: CRC Press Silva MC, Furlanetto TW. 2017. Intestinal absorption of vitamin D: a systematic review. Nutrition Review, 76(1): 60-76.

Shearer, M.J., Newman, P. 2014. Recent trends in the metabolism and cell biology of vitamin $\mathrm{K}$ with special reference to vitamin K cycling and MK-4 biosynthesis. Journal of Lipid Research 55: 345-362.

Shenkin, A. 2006. Micronutrients in health and disease. Postgrad. Med. J. 82(971): 559-567. https://dx.doi.org/10.1136\%2Fpgmj.2006.047670

Sikorski, Z.E. 1997. Chemical and Functional Properties of Food Components. Poland: Technomic Publishing. Pp. 119-160.

Sikalidis AK. 2018. From Food for Survival to Food for Personalized Optimal Health: A Historical Perspective of How Food and Nutrition Gave Rise to Nutrigenomics, Journal of the American College of Nutrition, DOI: 10.1080/07315724.2018.1481797

Singh, A.R., Singh, S.A. 2008. Diseases of poverty and lifestyle, well-being and human de velopment. Mens Sana Monogr. 6(1): 187-225. https://dx.doi.org/10.4103\%2F0973$\underline{1229.40567}$

Singh, R., Singh, G.S. 2017. Traditional agriculuture: a climate-smart approach for sustaina 
1391

1392

1393

1394

1395

1396

1397

1398

1399

1400

1401

1402

1403

1404

1405

1406

1407

1408

1409

1410

1411

1412

1413

1414

1415

1416

1417

1418

1419

1420

1421

1422

1423

1424

1425

1426

1427

1428

1429

ble food production. Energy, Ecology and Environment, 2: 296-316.

https://doi.org/10.1007/s40974-017-0074-7

Sinha, K.K. 2003. Malnutrition | The Problem of Malnutrition. In: Caballero, B. (ed.) Ency clopedia of Food Sciences and Nutrition ( $2^{\text {nd }}$ edition). Amsterdam, Netherland: Academic Press, Elsevier BV. Pp. 3660-3667. https://doi.org/10.1016/B0-12-227055-X/00727-6

Skerrett, P.J., Willett, W.C. 2010. Essentials of healthy eating: A guide. J. Midwifrey Wom ens Health 55(6): 492-501. https://doi.org/10.1016/j.jmwh.2010.06.019

Stover PJ, editors. Handbook of Vitamins. 5th ed. New York, USA: CRC Press, Taylor \& Francis Group.

Tandzi, N.L., Mutengwa, S.C. 2020. Factors affecting yield of crops. In: Amanullah (ed.) Agronomy - Climate Change and Food Security. IntechOpen. DOI: 10.5772/intechopen.90672

Tapsell, L.C., Neale, E.P., Satija, A., Hu, F.B. 2016. Foods, nutrients, and dietary patterns: In terconenctions and implications for dietary guidelines. Adv. Nutr. 7(3): 445-454.

Tsiaras, W.G., Weinstock, M.A. 2011. Factors influencing vitamin D status. Acta Derm Ve nereol. 91(2): 115-124. https://doi.org/10.2340/00015555-0980

Trueblood NA, Ramasamy R, Wang LF, Schaefer S. 2000. Niacin protects the isolated heart from ischemia-reperfusion injury. Am J Physiol Heart Circ Physiol 279: H764-71.

UNICEF. 2019. Vitamin A deficiency. In: UNICEF data: Monitoring thesituation of women and children. https://data.unicef.org/topic/nutrition/vitamin-a-deficiency/\#more--1724 (accessed 10 June 2021).

Upham, B. 2019. A New Study Suggests Supplements May Not Offer the Same Nutrient Benefits as Food. https://www.everydayhealth.com/diet-nutrition/study-nutrients-fromdiet-better-than-supplements/ (accessed 12 June 2021).

Uribe, N.G., Garcia-Galbis, M.R., Espinosa, R.M.M. 2017. New advances about the effect of vitamins on human health: Vitamins supplements and nutritional aspects. IntechOpen Publishers. http://www.doi.org/10.5772/intechopen.69122

Vannucchi, H. 1991. Interaction of vitamins and minerals. Arch. Latinoam Nutr. 41(1): 918.

Verstuyf A, Carmeliet G, Bouillon R, Mathieu C. 2010. Vitamin D: a pleiotropic hormone. Kidney Int. 78(2): 140-145. doi: 10.1038/ki.2010.17.

Wallert, M., Schmolz, L., Galli, F., Birringer, M. Lorkowski, S. 2014. Regulatory metabolites of vitamin $\mathrm{E}$ and their putative relevance for atherogenesis. Redox Biology, 2: 495-503.

Weininger, J. 2021. Vitamin. https://www.britannica.com/science/human-nutrition/Proteins (accessed 2 June 2021).

WHO/FAO. 1996. Preparation and Use of Food-Based Dietary Guidelines. Report of a joint FAO/WHO consultation, Nicosia, Cyprus 1996. Nutrition Program, World Health Organization, Geneva. WHO/NUT/96.6.

WHO/FAO. 2003. Diet, nutrition and the prevention of chronic diseases: Report of a Joint

Peer) reviewing PDF | (2021:03:59124:1:1:NEW 28 Jun 2021) 
1430

1431

1432

1433

1434

1435

1436

1437

1438

1439

1440

1441

1442

1443

1444

1445

1446

1447

1448

1449

1450

1451

1452

1453

1454

WHO/FAO Expert Consultation. WHO Technical Report Series, No. 916. World Health Organization, Geneva.

WHO. 2011. "Serum Retinol Concentrations for Determining the Prevalence of Vitamin A Deficiency in Populations." WHO/NMH/NHD/MNM/11.3. Vitamin and Mineral Nutrition Information System. Geneva, Switzerland: World Health Organization. http://www.who.int/vmnis/indicators/retinol.pdf.

Wusigale, Liang, L. 2020. Folates: Stability and interaction with biological molecules. Jour nal of Agriculture and Food Research, 2: 100039. https://doi.org/10.1016/j.jafr.2020.100039

Yoshimoto, S., Kohara, N., Sato, N., Ando, H., Ichihashi, M. 2020. Riboflavin plays a pivotal role in the UVA-induced cytotoxicity of fibroblasts as a key molecules in the production of $\mathrm{H}_{2} \mathrm{O}_{2}$ by UVA radiation in collaboration with amino acids and vitamins. International Journal of Molecular Sciences, 21: 554. https://doi.org/10.3390/ijms21020554

Zhang, Y.-R., Zhao, Y.-Q., Huang, J.-F. 2012. Retinoid-binding proteins: Similar protein ar chitecture bind similar ligands via completely different ways. PLos ONE 7(5): e36772. https://doi.org/10.1371/journal.pone.0036772.

Zhao, X., Zhang, M., Li, C., Jiang, X., Su, Y., Zhang, Y. 2019. Benefits of vitamins in the treatment of Parkinson's disease. Oxidative Medicine and Cellular Longevity. Article ID 9426867. https://doi.org/10.1155/2019/9426867

Zheng W, Teegarden D. Vitamin D. In: Zempleni J, Sutties JW, Gregory JF, Stover PJ, editors. Handbook of Vitamins. 5th ed. New York, USA: CRC Press, Taylor \& Francis Group.

Zuvarox T, Belletieri C. 2021. Malabsorption Syndromes. In: Continuing Education ActivityMedical Reference. Treasure Island, FL: StatPearls Publishing. https://www.ncbi.nlm.nih.gov/books/NBK553106/ (accessed 14 May, 2021). 
Figure 1

Classifications of Vitamins

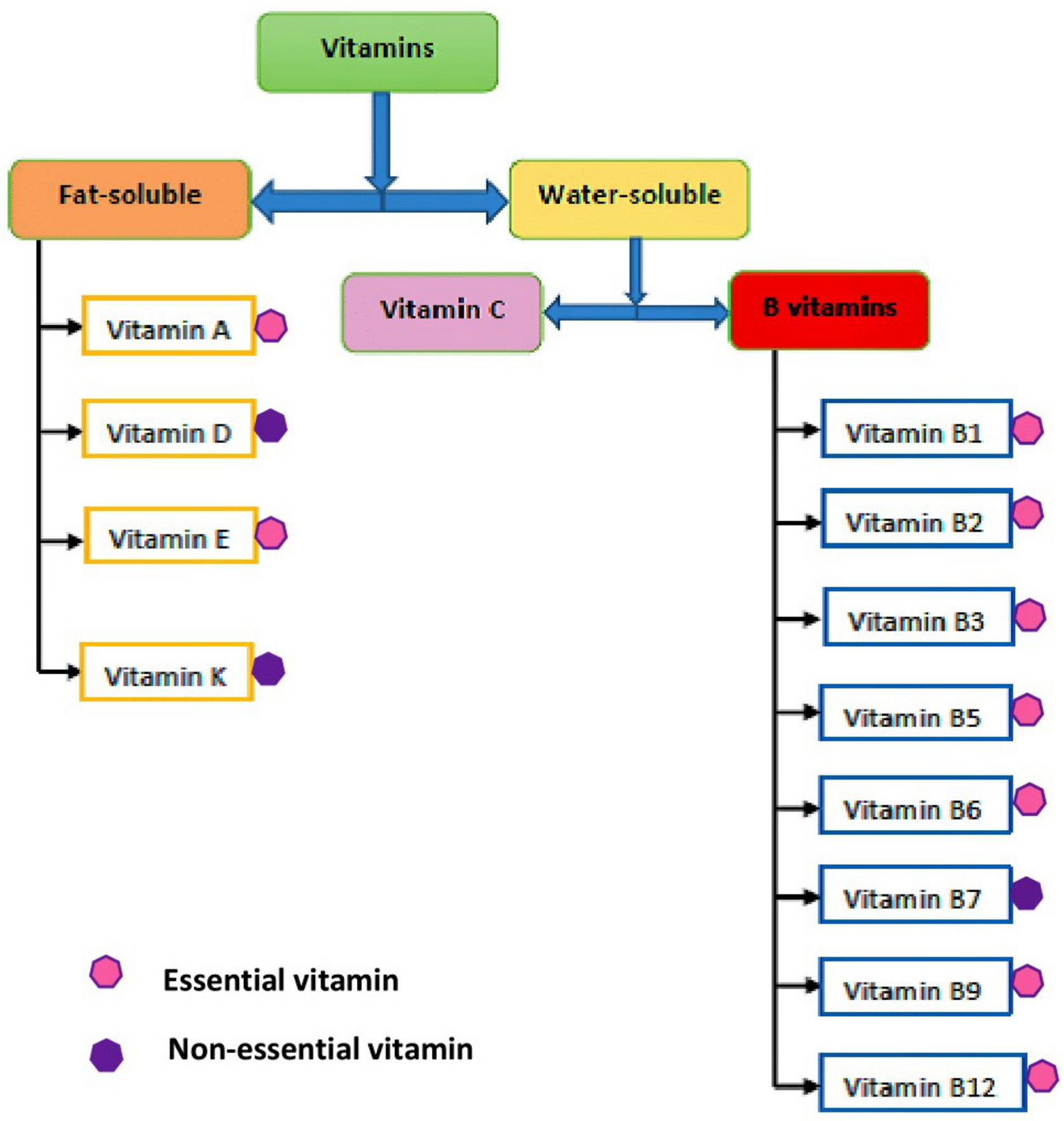




\section{Figure 2}

Chemical structures of vitamins

Footnote: A: Vitamin A (Retinol); B: Vitamin D (Ergocalciferol); C: Vitamin E ( $\alpha$-Tocopherol); D:

Vitamin K - (i) Phylloquinone (ii.) Menaquinone (iii.) Menadione; E: Vitamin B1 (Thiamine); F:

Vitamin B2 (Riboflavin); G: Vitamin B3 (Niacin); H: Vitamin B5 (Pantothenic acid); I: Vitamin B6 (Pyridoxine); J: Vitamin B7 (Biotin); K: Vitamin B9 (Folate); L: Vitamin B12 (Cobalamin); M: Vitamin C (Ascorbic acid) 
A<smiles>CC1=C(/C=C/C(C)=C/C=C/C(C)=C/CO)C(C)(C)CCC1</smiles><smiles>CC(C)(CO)C(O)C(=O)NCCC(=O)O</smiles>

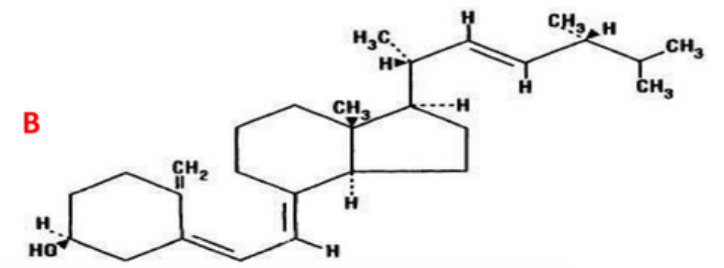<smiles>Cc1ncc(CO)c(CO)c1O</smiles><smiles>O=C(O)CCCCC1SC[C@@H]2NC(=O)NC12</smiles>

C<smiles>Cc1c(C)c2c(c(C)c1O)CC[C@@](C)(CCC[C@H](C)CCC[C@H](C)CCCC(C)C)O2</smiles>

D<smiles>CC(C=CC1=C(C)C(=O)c2ccccc2C1=O)=CCCC[C@H](C)CCC[C@@H](C)CCCC(C)C</smiles><smiles>CC(C)=CCCC(C)(C)C(C)=CCC1=C(C)C(=O)c2ccccc2C1=O</smiles><smiles>CC1=CC(=O)c2ccccc2C1=O</smiles>

E<smiles></smiles>

$\mathbf{F}$<smiles>Cc1cc2c(cc1Cl)N(C[C@H](O)[C@H](O)[C@H](O)CO)C(C(N)=O)=NC(=O)NC2=O</smiles>

G<smiles>O=C(O)c1cccnc1</smiles><smiles>Nc1nc2ncc(CNc3ccc(C(=O)NC(CCC(=O)O)C(=O)O)cc3)nc2c(=O)[nH]1</smiles>

K

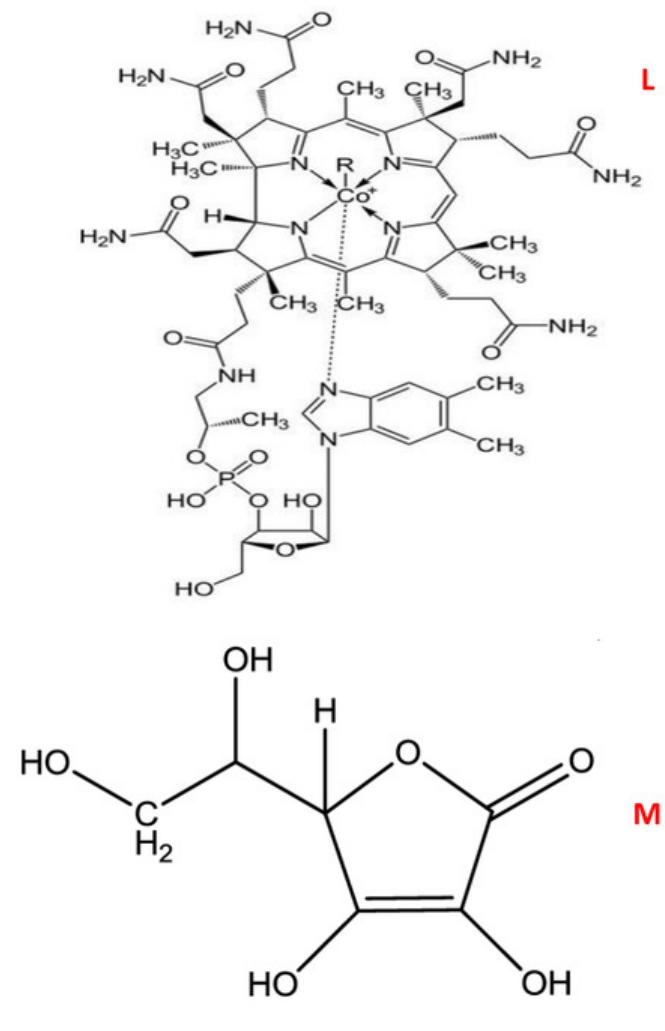


Figure 3

Flow diagram showing the absorption of vitamins

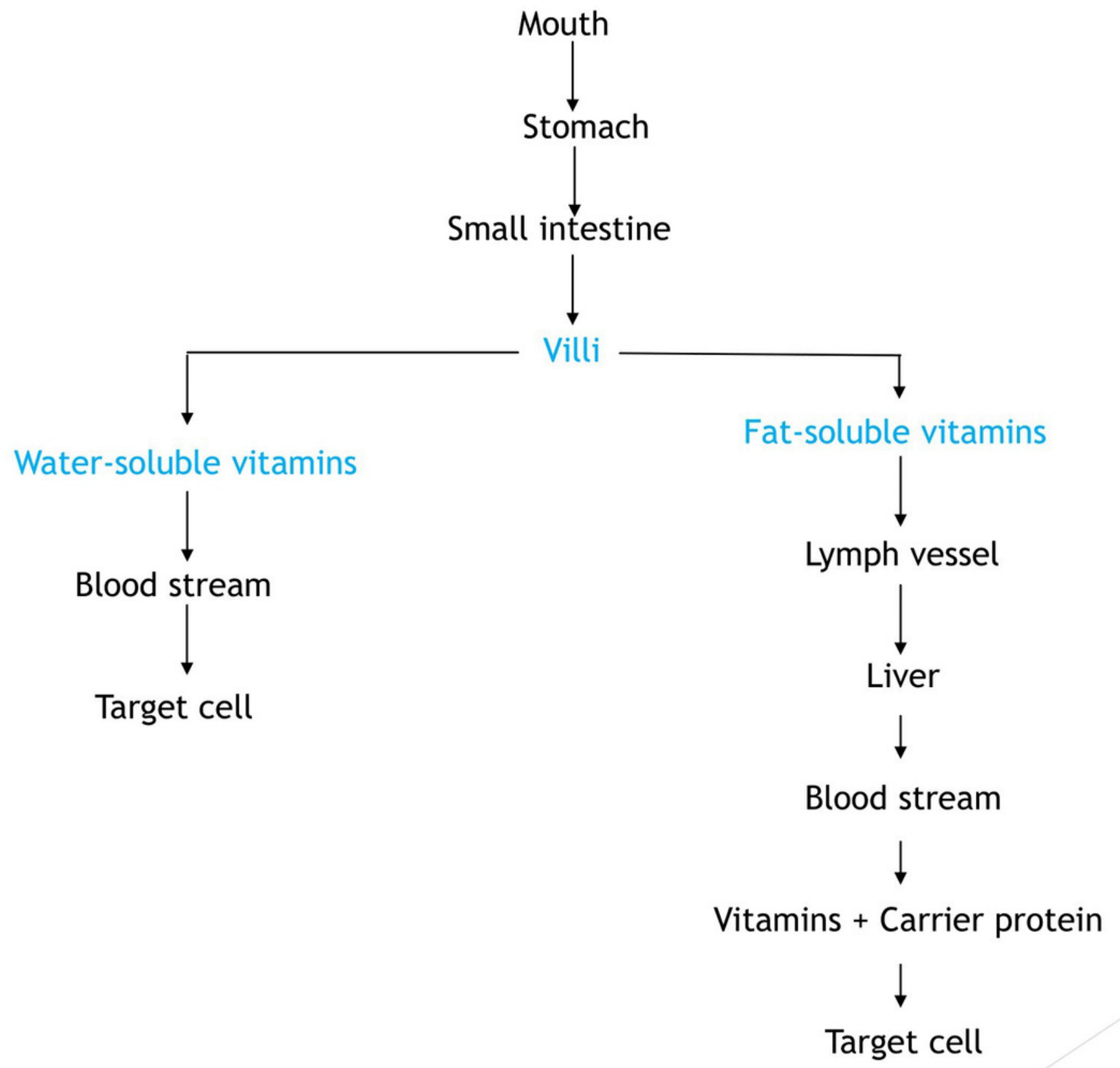


Figure 4

Factors that interact with food-sourced vitamins

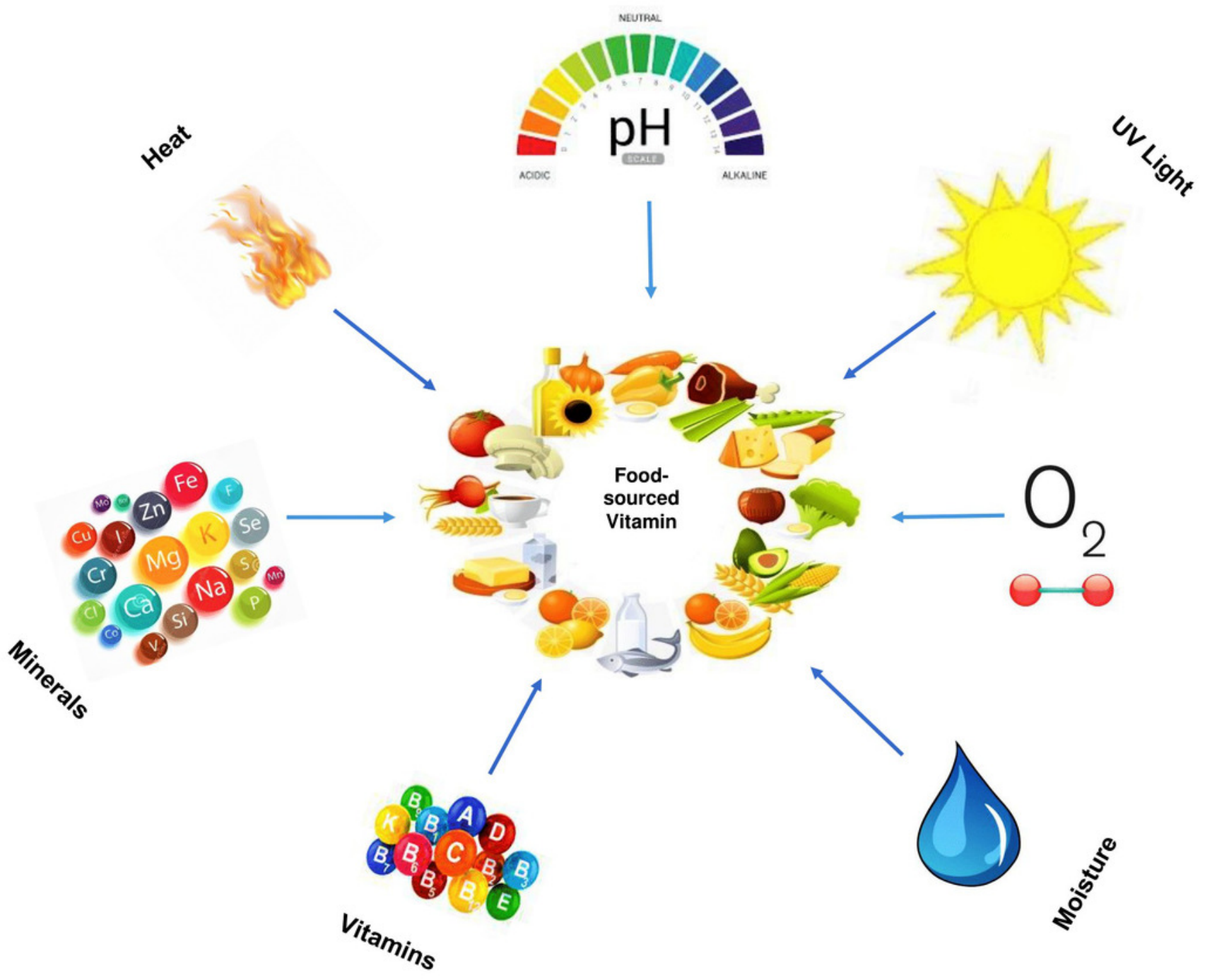


Table $\mathbf{1}$ (on next page)

Prevalence of the most common global vitamin deficiency.

Values are the amount of blood serum vitamin. 
1

2 Table 1: Prevalence of the most common global vitamin deficiency

\begin{tabular}{|c|c|c|c|c|c|}
\hline Vitamin & $\begin{array}{l}\text { Prevalence of } \\
\text { deficiency }\end{array}$ & Sufficiency & Hypovitaminosis & Deficiency & Reference (s) \\
\hline B12 & $>50 \%$ & $>221 \mathrm{pmol} / \mathrm{L}$ & $\leq 148-221 \mathrm{pmol} / \mathrm{L}$ & $<148 \mathrm{pmol} / \mathrm{L}$ & $\begin{array}{l}\text { WHO (2008); Guney, } \\
\text { Yikilmaaz \& Dilek (2016); } \\
\text { Allen et al., (2018) }\end{array}$ \\
\hline A & $13 \%$ & $>0.83 \mu \mathrm{mol} / \mathrm{L}$ & $\leq 0.71-0.83 \mu \mathrm{mol} / \mathrm{L}$ & $<0.70 \mu \mathrm{mol} / \mathrm{L}$ & $\begin{array}{l}\text { WHO (2011); Akhtar et al. } \\
\text { (2013) }\end{array}$ \\
\hline B9 & $>20 \%$ & $>30 \mathrm{nmol} / \mathrm{L}$ & - & $<10 \mathrm{nmol} / \mathrm{L}$ & $\begin{array}{l}\text { WHO (2008); Bailet et al., } \\
\text { (2015); Rogers et al., (2018) }\end{array}$ \\
\hline $\mathrm{D}$ & $>20 \%$ & $50-100 \mathrm{nmol} / \mathrm{L}$ & $\leq 30-50 \mathrm{nmol} / \mathrm{L}$ & $<30 \mathrm{nmol} / \mathrm{L}$ & Roth et al., (2018) \\
\hline $\mathrm{C}$ & $>1.4 \%$ & $50-75 \mu \mathrm{mol} / \mathrm{L}$ & $\leq 23-28 \mu \mathrm{mol} / \mathrm{L}$ & $<11 \mu \mathrm{mol} / \mathrm{L}$ & Rowe \& Carr (2020) \\
\hline $\mathrm{E}$ & & $23-73 \mu \mathrm{mol} / \mathrm{L}$ & - & $<17 \mu \mathrm{mol} / \mathrm{L}$ & $\begin{array}{l}\text { Institute of Medicine (2000): } \\
\text { Charbek (2014) }\end{array}$ \\
\hline
\end{tabular}

3 Note: Values are the amount of blood serum vitamin 
Table 2 (on next page)

Metabolic functions of vitamins.

Source: Adapted from Combs (2008). 
1 Table 2. Metabolic functions of vitamins

\begin{tabular}{|c|c|}
\hline Vitamins & Functions \\
\hline A & $\begin{array}{l}\text { Promotes good vision, produces visual pigments in the retina of the eye, and participates in epithelial cell } \\
\text { differentiation. }\end{array}$ \\
\hline $\mathrm{D}$ & $\begin{array}{l}\text { Regulates bone metabolism, mineralization of bones via osteoblasts, and increases calcium and phosphate } \\
\text { absorption in the intestine. }\end{array}$ \\
\hline $\mathrm{E}$ & Possess membrane antioxidant capacity \\
\hline K & Important for blood clotting and calcium metabolism for bone health \\
\hline $\mathrm{C}$ & $\begin{array}{l}\text { Acts as an antioxidant in tissue and plasma, promotes growth and repair of tissues, essential for the } \\
\text { synthesis of collagen and carnitine. }\end{array}$ \\
\hline B1 & $\begin{array}{l}\text { Vital for energy metabolism, nerve and muscle activity, forms important coenzymes for decarboxylations } \\
\text { of 2-keto-acids and transketolations. }\end{array}$ \\
\hline B2 & $\begin{array}{l}\text { Forms an important coenzyme in oxidation-reduction reactions of fatty acids and tricarboxylic acid } \\
\text { (TCA) cycle, essential for energy metabolism and synthesis of neurotransmitters. }\end{array}$ \\
\hline B3 & $\begin{array}{l}\text { Essential for energy metabolism and neurological processes, an important coenzyme for several } \\
\text { dehydrogenases. }\end{array}$ \\
\hline B5 & $\begin{array}{l}\text { Essential for wound healing and normalizing blood lipid profile, an important coenzyme in fatty acid } \\
\text { metabolism. }\end{array}$ \\
\hline B6 & $\begin{array}{l}\text { Important for nerve activity, acts as coenzymes in amino acid metabolism, fundamental in the synthesis of } \\
\text { neurotransmitters, DNA and haemoglobin. }\end{array}$ \\
\hline B7 & $\begin{array}{l}\text { Important coenzyme for carboxylation and in lipid metabolism, essential for hair, skin and nail } \\
\text { regeneration. }\end{array}$ \\
\hline B9 & $\begin{array}{l}\text { Vital coenzyme in single-carbon metabolism and synthesis of DNA, necessary for red blood cell } \\
\text { production and neural tube formation. }\end{array}$ \\
\hline B12 & $\begin{array}{l}\text { Necessary for folate coenzyme function, red blood cell formation, and absorption of iron, calcium and } \\
\text { vitamin A, essential in nerve activity and synthesis of neurotransmitters. }\end{array}$ \\
\hline
\end{tabular}

2 Source: Adapted from Combs (2008). 


\section{Table 3(on next page)}

Major food sources of vitamins available for the human diet and recommended amount of daily adequate intake.

Source: Adapted from SAL (2017); Uribe, Garcia-Galbis \& Espinosa (2017), and Harvard Medical School (2020) Abbreviation: Al, Adequate Intake 
1 Table 3. Major food sources of vitamins available for the human diet and recommended amount of daily

2 adequate intake

\begin{tabular}{|c|c|c|}
\hline Vitamin & Food sources & $\begin{array}{l}\text { Recommended Amount } \\
\text { ( Daily AI) }\end{array}$ \\
\hline A & $\begin{array}{l}\text { Retinol: Fish, butter, whole milk, egg yolk, and cheese. } \\
\text { Carotenoids: Carrots, orange-flesh sweet potatoes, orang- flesh fruits } \\
\text { (melon, mangoes, \& persimmons), green leafy vegetables (i.e. spinach, } \\
\text { broccoli, etc.), pumpkins, and red palm oil. }\end{array}$ & $\begin{array}{c}700-900 \mu \mathrm{g} \\
(2333-3000 \mathrm{IU})\end{array}$ \\
\hline $\mathrm{D}$ & $\begin{array}{l}\text { Sun ultraviolet B radiation, beef, egg, yolk, veal, mushrooms, liver, fortified } \\
\text { cereal and dairy products, fatty fish, and fat spreads. }\end{array}$ & $\begin{array}{c}15-20 \mu \mathrm{g} \\
(600-800 \mathrm{IU})\end{array}$ \\
\hline $\mathrm{E}$ & $\begin{array}{l}\text { Edible vegetable oils, nuts (almonds, peanuts) and nut spreads, avocado, } \\
\text { sunflower seeds, fruits (mango, kiwifruit), meats, and leafy green } \\
\text { vegetables (spinach, chard). }\end{array}$ & $\begin{array}{c}15 \mu \mathrm{g} \\
(22-33 \mathrm{IU})\end{array}$ \\
\hline $\mathrm{K}$ & $\begin{array}{l}\text { Phylloquinone: Spinach, broccoli, vegetable oils (soybean, canola, olive), } \\
\text { green leafy vegetables (parsley, spinach, collard greens, and salad greens), } \\
\text { and cabbage. } \\
\text { Menaquinone: Natto (fermented soybeans, fermented cheese and curds. }\end{array}$ & $90-120 \mu \mathrm{g}$ \\
\hline $\mathrm{C}$ & $\begin{array}{l}\text { Fruits (especially citrus fruits), green leafy vegetables, potatoes, cabbage- } \\
\text { type vegetable, liver (lamb and chicken), tomatoes, brussels sprouts, } \\
\text { broccoli, and lettuce. }\end{array}$ & $75-90 \mathrm{mg}$ \\
\hline B1 & $\begin{array}{l}\text { Citrus fruits (orange juice, strawberries, grape, pineapple, etc.), offal (liver, } \\
\text { heart, kidneys), fish, meat (pork), asparagus, green leafy vegetables, whole } \\
\text { grain cereals, legumes (lentils and beans), nuts, brewer's yeast, squash, and } \\
\text { soymilk. }\end{array}$ & $1.1-1.2 \mathrm{mg}$ \\
\hline $\mathrm{B} 2$ & $\begin{array}{l}\text { Brewer's yeast, meat (beef, pork), nuts, dark green leafy vegetables, eggs, } \\
\text { milk, yoghurt, offal (liver, kidneys, heart), \& whole grains cereals. }\end{array}$ & $1.1-1.3 \mathrm{mg}$ \\
\hline B3 & $\begin{array}{l}\text { Dairy milk, egg, meat, fish, offal (liver), yogurt, cheese, legumes, fruits } \\
\text { (dates, fogs, prunes, and avocados), mushrooms, nuts and others } \\
\text { (synthesized from tryptophan). }\end{array}$ & $14-16 \mathrm{mg}$ \\
\hline B5 & $\begin{array}{l}\text { Brewer's yeast, meat, poultry, red fish, cereals, legumes, egg yolk, milk, } \\
\text { offals (liver, kidneys), tomatoes, potatoes, broccoli, mushroom, and green } \\
\text { leafy vegetables. }\end{array}$ & $5 \mathrm{mg}$ \\
\hline B6 & Broccoli, fish, shellfish, chicken, milk, yogurt, \& mushrooms. & $1.3-1.7 \mathrm{mg}$ \\
\hline B7 & $\begin{array}{l}\text { Chicken, fish (tuna, salmon), beef, liver, nuts (peanut, walnut), chickpeas, } \\
\text { maize and whole grain cereals, green leafy vegetables, bananas, potatoes, } \\
\text { other meat organs, fruits, and starchy vegetables }\end{array}$ & $30 \mu \mathrm{g}$ \\
\hline B9 & $\begin{array}{l}\text { Nuts (walnuts, peanuts), cereals, milk, lentils, wheat germ, yeast, asparagus, } \\
\text { beans, green leafy vegetable, and egg yolks }\end{array}$ & $400 \mu \mathrm{g}$ \\
\hline B12 & $\begin{array}{l}\text { Shellfish, liver, game meat (venison and rabbit), milk and milk products, } \\
\text { some fish (salmon, trout, herring and sardines) Spinach, dark leafy greens, } \\
\text { asparagus, beets, turnips, \& mustard greens }\end{array}$ & $2.4 \mu \mathrm{g}$ \\
\hline
\end{tabular}


3 Source: Adapted from SAL (2017); Uribe, Garcia-Galbis \& Espinosa (2017), and Harvard Medical School (2020)

4 Abbreviation: AI, Adequate Intake 


\section{Table 4 (on next page)}

Absorption mechanism and post-absorptive transport of vitamins in the body.

Abbreviations: $D=$ duodenum; J = jejunum; I = ileum, VLDL = Very low density lipoprotein, $\mathrm{HDL}=$ High density lipoprotein, $\mathrm{BP}=$ Binding protein, $\mathrm{RBP}=$ Retinol $\mathrm{BP}, \mathrm{CRBP}=$ Cellular $\mathrm{RBP}$, $\mathrm{CRBPII}=$ Cellular RBP, type II, IRBP $=$ Interstitial RBP, CRALBP $=$ Cellular retinal $\mathrm{BP}, \mathrm{CRABP}=$ Cellular retinoic acid BP (Source: Adapted from Combs, 2008). 
1 Table 4. Absorption mechanism and post-absorptive transport of vitamins in the body

\begin{tabular}{|c|c|c|c|c|c|}
\hline \multirow[b]{2}{*}{ Vitamin } & \multicolumn{2}{|l|}{$\begin{array}{l}\text { Enteric vitamin } \\
\text { absorption }\end{array}$} & \multicolumn{3}{|c|}{ Vehicle } \\
\hline & $\begin{array}{l}\text { Enterocytic } \\
\text { metabolism }\end{array}$ & Site & Absorption & Transport & Cellular uptake \\
\hline A & $\begin{array}{l}\text { Micelle-dependent } \\
\text { diffusion }\end{array}$ & $\mathrm{D}, \mathrm{J}$ & $\begin{array}{l}\text { Retinol: Passive diffusion } \\
\text { Carotenoid: Facilitated } \\
\text { diffusion }\end{array}$ & $\begin{array}{l}\text { Lipoprotein carrier } \\
\text { (chylomicron), specific } \\
\text { binding protein (RBP, } \\
\text { CRBP. CRBPII, IRBP, } \\
\text { CRALBP \& CRABP) }\end{array}$ & Facilitated transport \\
\hline $\mathrm{D}$ & $\begin{array}{l}\text { Micelle-dependent } \\
\text { diffusion }\end{array}$ & $\mathrm{D}, \mathrm{J}$ & Passive diffusion & $\begin{array}{l}\text { Lipoprotein carrier } \\
\text { (chylomicron), Specific } \\
\text { binding protein } \\
\text { (Transcalciferin, vitamin D } \\
\text { receptor) }\end{array}$ & $\begin{array}{l}\text { Passive } \\
\text { diffusion }\end{array}$ \\
\hline $\mathrm{E}$ & $\begin{array}{l}\text { Micelle-dependent } \\
\text { diffusion }\end{array}$ & $\mathrm{D}, \mathrm{J}$ & Passive diffusion & $\begin{array}{l}\text { Lipoprotein carrier } \\
\text { (Chylomicron, VLDL/HDL), } \\
\text { specific binding protein } \\
\text { (vitamin E BP), Erythrocyte } \\
\text { carried (Erythrocyte } \\
\text { membranes) }\end{array}$ & Facilitated transport \\
\hline \multirow[t]{2}{*}{ K } & $\begin{array}{l}\text { K2 and K3: Micelle- } \\
\text { dependent diffusion }\end{array}$ & $\mathrm{D}, \mathrm{J}$ & Passive diffusion & $\begin{array}{l}\text { Lipoprotein carrier } \\
\text { (Chylomicron, VLDL/HDL) }\end{array}$ & $\begin{array}{l}\text { Passive } \\
\text { diffusion }\end{array}$ \\
\hline & K1: Active transport & $\mathrm{D}, \mathrm{J}$ & & & \\
\hline \multirow[t]{2}{*}{$\mathrm{C}$} & Active transport & I & $\begin{array}{l}\text { Passive diffusion, Carrier- } \\
\text { mediated diffusion }\end{array}$ & $\begin{array}{l}\text { Free in plasma } \\
\text { (Erythrocytes) }\end{array}$ & $\begin{array}{l}\text { Simple } \\
\text { diffusion }\end{array}$ \\
\hline & Simple diffusion & D, J, & & & \\
\hline \multirow[t]{2}{*}{ B1 } & Active transport & $\mathrm{D}$ & Passive diffusion & $\begin{array}{l}\text { Free in plasma } \\
\text { (Erythrocytes) }\end{array}$ & \multirow{2}{*}{$\begin{array}{l}\text { Passive diffusion, } \\
\text { Carrier-mediated } \\
\text { transport }\end{array}$} \\
\hline & Simple diffusion & $\mathrm{J}$ & & & \\
\hline B2 & Active transport & $\mathrm{J}$ & $\begin{array}{l}\text { Carrier-mediated } \\
\text { diffusion, Passive } \\
\text { diffusion }\end{array}$ & $\begin{array}{l}\text { Free in plasma } \\
\text { (Erythrocytes), non-specific } \\
\text { carrier proteins (Albumin, } \\
\text { Immunoglobulins), Specific } \\
\text { binding proteins (Riboflavin } \\
\text { BP, flavoproteins) }\end{array}$ & $\begin{array}{l}\text { Carrier-mediated } \\
\text { transport }\end{array}$ \\
\hline \multirow[t]{2}{*}{ B3 } & Facilitated diffusion & $\mathrm{J}$ & $\begin{array}{l}\text { Passive diffusion, } \\
\text { Facilitated diffusion }\end{array}$ & $\begin{array}{l}\text { Free in plasma } \\
\text { (Erythrocytes) }\end{array}$ & $\begin{array}{l}\text { Passive } \\
\text { diffusion }\end{array}$ \\
\hline & Simple diffusion & $\mathrm{J}$ & & & \\
\hline \multirow[t]{2}{*}{ B5 } & Facilitated diffusion & $\mathrm{J}$ & Passive diffusion & $\begin{array}{l}\text { Free in plasma } \\
\text { (Erythrocytes) }\end{array}$ & $\begin{array}{l}\text { Carrier-mediated } \\
\text { transport }\end{array}$ \\
\hline & Simple diffusion & $\mathrm{J}$ & & & \\
\hline
\end{tabular}




\begin{tabular}{|c|c|c|c|c|c|}
\hline B6 & Simple diffusion & $\mathrm{J}$ & $\begin{array}{l}\text { Passive diffusion, Carrier- } \\
\text { mediated diffusion }\end{array}$ & $\begin{array}{l}\text { Erythrocyte carried } \\
\text { (Erythrocyte membrane), } \\
\text { non-specific carrier proteins } \\
\text { (Albumin) }\end{array}$ & Passive diffusion \\
\hline \multirow[t]{2}{*}{ B7 } & Facilitated diffusion & $\mathrm{J}$ & $\begin{array}{l}\text { Facilitated diffusion, } \\
\text { Passive diffusion }\end{array}$ & $\begin{array}{l}\text { Free in plasma } \\
\text { (Erythrocytes) }\end{array}$ & \multirow{2}{*}{$\begin{array}{l}\text { Facilitated transport, } \\
\text { Carrier-mediated } \\
\text { transport }\end{array}$} \\
\hline & Simple diffusion & $\mathrm{D}, \mathrm{J}$ & & & \\
\hline B9 & Simple diffusion & $\mathrm{J}$ & $\begin{array}{l}\text { Passive diffusion, Carrier- } \\
\text { mediated diffusion }\end{array}$ & $\begin{array}{l}\text { Free in plasma } \\
\text { (Erythrocytes) }\end{array}$ & Facilitated transport \\
\hline B12 & Simple diffusion & $\mathrm{D}, \mathrm{J}$ & Passive diffusion & $\begin{array}{l}\text { Specific binding proteins } \\
\text { (Transcobalamin I, } \\
\text { Transcobalamin II, } \\
\text { Transcobalamin III) }\end{array}$ & $\begin{array}{l}\text { Passive } \\
\text { diffusion }\end{array}$ \\
\hline
\end{tabular}

3 Abbreviations: $\mathrm{D}=$ duodenum; $\mathrm{J}=$ jejunum; $\mathrm{I}=$ ileum, $\mathrm{VLDL}=$ Very low density lipoprotein, $\mathrm{HDL}=$ High density lipoprotein, $\mathrm{BP}=$ 4 Binding protein, $\mathrm{RBP}=$ Retinol BP, CRBP $=$ Cellular RBP, CRBPII $=$ Cellular RBP, type II, IRBP $=$ Interstitial RBP, CRALBP $=$ 5 Cellular retinal BP, CRABP = Cellular retinoic acid BP (Source: Adapted from Combs, 2008). 
Table 5 (on next page)

Vitamin deficiency.

Source: Adapted from Combs (2008); Johnson (2020). 
1 Table 5. Vitamin deficiency

\begin{tabular}{ll}
\hline Vitamin type & Deficiency \\
\hline A & $\begin{array}{l}\text { Bitot spot and Nyctalopia (Night blindness), Xerophtalmia, dry mucous memberanes, keratinization of } \\
\text { the corneal epithelium }\end{array}$ \\
D & Osteoporosis, Osteomalacia in adults, and rickets in children \\
E & $\begin{array}{l}\text { Retrolental fibroplasia (Retinal degeneration), Vision problems, weakened immune system, nerve \& } \\
\text { muscle damage. }\end{array}$ \\
K & Bleeding disorders \\
C & Scurvy \\
B1 & Beriberi and Wernicke-Korsakoff syndrome \\
B2 & Ariboflavinosis resulting in sore throat, skin disorders, edema of the mouth \& throat. \\
B3 & Pellagra \\
B5 & $\begin{array}{l}\text { Deficiency is rare but may include symptoms like fatigue, insomnia, depression, vomiting, stomach } \\
\text { pains, upper respiratory infections, etc. }\end{array}$ \\
B6 & $\begin{array}{l}\text { Deficiency is rare but may include symptoms like skin rashes, cracked lips, a glossy tongue, tiredness, } \\
\text { mouth sores, nerve pain, confusion, etc. }\end{array}$ \\
B7 & Deficiency is rare but may include symptoms like hair loss, scaly red rash on the face, etc. \\
B9 & Spina bifida and anaemia \\
Neurological difficulties, macrocytic anaemia, and neural-tube defects.
\end{tabular}

2 Source: Adapted from Combs (2008); Johnson (2020).

3 
Table 6(on next page)

Vitamin toxicity.

Source: Adapted from Delaney \& Barke (2017); Davidson (1984); Evans \& Lacey (1986);

Picincu (2021). 


\section{Table 6. Vitamin toxicity}

\begin{tabular}{|c|c|}
\hline Vitamin type & Toxicity \\
\hline A & $\begin{array}{l}\text { Overdose can lead to Raised intracranial pressure ("Pseudotumour cerebri"), Chronic liver disease, } \\
\text { Hair loss, Ingrowing toe nails resistant to treatment; Tenderness of bones; Birth defects; Weight } \\
\text { loss; Anorexia; Alopecia; Diplopia }\end{array}$ \\
\hline $\mathrm{D}$ & $\begin{array}{l}\text { Overdose can lead to Hypercalcaemia, Hypertension, Hypercalciuria, Renal calcinosis, Metastatic } \\
\text { calcification, cardiovascular damage }\end{array}$ \\
\hline $\mathrm{E}$ & $\begin{array}{l}\text { Overdose can lead to increased anticoagulant action of warfarin, gastrointestinal distress, } \\
\text { gaemorrhagic toxicity, nausea, muscular pain, fatigue, double vision, creatinurea }\end{array}$ \\
\hline K & Overdose can lead to Haemolytic anaemia and Neonatal jaundice \\
\hline $\mathrm{C}$ & $\begin{array}{l}\text { Overdose can lead to oxalate stones in predisposed individuals, possible teratogenesis and } \\
\text { carcinogenesis, a multiplicity of minor idiosyncratic symptoms }\end{array}$ \\
\hline B1 & Overdose can lead to stomach upset, nausea, vomiting, and diarrhea \\
\hline B2 & No known toxicity since higher intakes are excreted in the urine and not stored. \\
\hline B3 & $\begin{array}{l}\text { Overdose can lead to peptic ulcer, Alopecia, Arrhythmias, Hepatotoxicity, Hypotension, and } \\
\text { Pruritus }\end{array}$ \\
\hline B5 & $\begin{array}{l}\text { Common side effects when administered can include abdominal pain, constipation, creatine } \\
\text { phosphokinase (CPK) increase, dizziness/weakness, flulike illness, joint/muscle pain, nausea, } \\
\text { pancreatitis, sore throat }\end{array}$ \\
\hline B6 & $\begin{array}{l}\text { Overdosage can lead to dependency, peripheral sensory neuropathy, and ataxia, decrease in the } \\
\text { therapeutic effect of levodopa }\end{array}$ \\
\hline B7 & $\begin{array}{l}\text { Overdosage can lead to skin allergies characterized by flushing, rashes, and itchiness; increased } \\
\text { risk for anaphylaxis; insomnia, lower vitamin C and B6 levels, and excessive thirst and/or } \\
\text { urination; eosinophilic pleuropericardial effusion }\end{array}$ \\
\hline B9 & $\begin{array}{l}\text { Overdosage can cause gastrointestinal defects, loss of appetite, mental confusion, nausea, seizures, } \\
\text { skin reactions, and sleep disturbances }\end{array}$ \\
\hline B12 & $\begin{array}{l}\text { No known toxicity however vitamin B complex requires caution when taken with vitamins B5 and } \\
\text { B6. The former (that is vitamin B5) may cause vascular dilation, itching, nausea, headache, liver } \\
\text { damage, and inflammation of the gastric mucosa. The latter (that is vitamin B6) from } 2 \text { grams or } \\
\text { more can lead to movement and nervous disorders. }\end{array}$ \\
\hline
\end{tabular}




\section{Table 7 (on next page)}

Vitamin intake from various foods and the prevalence of potential dietary supplementation.

Source: Adapted from Drake (2017); Delaney \& Barke (2017); Harvard Medical School (2020). Abbreviations: RAE, retinol activity equivalents; DFE, dietary folate equivalents; RDA, recommended dietary allowance; UL, upper limit; EAS, estimated amount of supplementation; NSR, no supplementation required. 
1 Table 7: Vitamin intake from various foods and the prevalence of potential dietary supplementation

\begin{tabular}{|c|c|c|c|c|c|c|}
\hline Vitamin & Food source & $\begin{array}{c}\text { Average } \\
\text { amount of } \\
\text { vitamin in } \\
\text { food }\end{array}$ & $\begin{array}{l}\text { Mean daily } \\
\text { intake from } \\
\text { food }\end{array}$ & Mean RDA & UL per day & EAS (\%) \\
\hline A & $\begin{array}{l}\text { Milk, whole } \\
\text { Cheddar cheese } \\
\text { Chicken liver } \\
\text { Beef liver }\end{array}$ & $\begin{array}{l}6.2 \mu \mathrm{g} \\
7.1 \mu \mathrm{g} \\
308 \mu \mathrm{g} \\
679 \mu \mathrm{g}\end{array}$ & $424 \mu \mathrm{g}$ RAE & $800 \mu \mathrm{g}$ & $3000 \mu \mathrm{g}$ & $47 \%$ \\
\hline D & $\begin{array}{l}\text { Sardines, canned } \\
\text { in oil } \\
\text { Egg, large } \\
\text { Beef liver } \\
\text { Milk, non-fat, } \\
\text { vitamin-D fortified }\end{array}$ & $\begin{array}{l}1.15 \mu \mathrm{g} \\
\\
1.03 \mu \mathrm{g} \\
1.05 \\
3.10 \mu \mathrm{g}\end{array}$ & $2.0 \mu \mathrm{g}$ & $18 \mu \mathrm{g}$ & $50 \mu \mathrm{g}$ & $89 \%$ \\
\hline $\mathrm{E}$ & $\begin{array}{l}\text { Sunflower seeds } \\
\text { Almonds } \\
\text { Peanuts } \\
\text { Sunflower oil }\end{array}$ & $\begin{array}{l}7.4 \mathrm{mg} \\
6.8 \mathrm{mg} \\
2.2 \mathrm{mg} \\
5.6 \mathrm{mg}\end{array}$ & $6.8 \mathrm{mg}$ & $15 \mu \mathrm{g}$ & $1000 \mathrm{mg}$ & $55 \%$ \\
\hline K & $\begin{array}{l}\text { Broccoli } \\
\text { Cabbage } \\
\text { Ground beef } \\
\text { Spinach }\end{array}$ & $\begin{array}{c}160 \mu \mathrm{g} \\
34 \mu \mathrm{g} \\
6 \mu \mathrm{g} \\
27 \mu \mathrm{g}\end{array}$ & $86.7 \mu \mathrm{g}$ & $105 \mu \mathrm{g}$ & Not known & $17 \%$ \\
\hline & $\begin{array}{l}\text { Breakfast cereals, } \\
\text { fortified }\end{array}$ & $1.5 \mathrm{mg}$ & & & & \\
\hline B1 & $\begin{array}{l}\text { Pork, broiled } \\
\text { White rice, } \\
\text { enriched } \\
\text { Tuna, cooked }\end{array}$ & $\begin{array}{l}0.4 \mathrm{mg} \\
1.4 \mathrm{mg} \\
0.2 \mathrm{mg}\end{array}$ & $0.9 \mathrm{mg}$ & $1.2 \mathrm{mg}$ & Not known & $25 \%$ \\
\hline B2 & $\begin{array}{l}\text { Beef liver } \\
\text { Egg. Scrambled } \\
\text { Plain yoghurt, fat } \\
\text { free } \\
\text { Instant oats, } \\
\text { fortified }\end{array}$ & $\begin{array}{l}2.9 \mathrm{mg} \\
0.2 \mathrm{mg} \\
0.6 \mathrm{mg} \\
1.1 \mathrm{mg}\end{array}$ & $1.7 \mathrm{mg}$ & $1.2 \mathrm{mg}$ & Not known & NSR \\
\hline B3 & $\begin{array}{l}\text { Turkey } \\
\text { Whole wheat bread } \\
\text { Cereal (fortified) } \\
\text { Tuna }\end{array}$ & $\begin{array}{l}10 \mathrm{mg} \\
1.3 \mathrm{mg} \\
20 \mathrm{mg} \\
8.6 \mathrm{mg}\end{array}$ & $18.5 \mathrm{mg}$ & $15 \mathrm{mg}$ & $35 \mathrm{mg}$ & NSR \\
\hline B5 & $\begin{array}{l}\text { Avocado } \\
\text { Fish, trout } \\
\text { Egg } \\
\text { Yoghurt, plain } \\
\text { non-fat }\end{array}$ & $\begin{array}{l}1 \mathrm{mg} \\
1.9 \mathrm{mg} \\
0.7 \mathrm{mg} \\
1.6\end{array}$ & Not known & $5 \mathrm{mg}$ & Not known & - \\
\hline B6 & $\begin{array}{l}\text { Chickpeas } \\
\text { Tuna, fresh } \\
\text { Potatoes }\end{array}$ & $\begin{array}{l}1.1 \mathrm{mg} \\
0.9 \mathrm{mg} \\
0.4 \mathrm{mg}\end{array}$ & $1.6 \mathrm{mg}$ & $1.5 \mathrm{mg}$ & $100 \mathrm{mg}$ & NSR \\
\hline
\end{tabular}




\begin{tabular}{|c|c|c|c|c|c|c|}
\hline & Spinach & $0.1 \mathrm{mg}$ & & & & \\
\hline B7 & $\begin{array}{l}\text { Banana } \\
\text { Pork chop } \\
\text { Broccoli } \\
\text { Sweet potato }\end{array}$ & $\begin{array}{l}0.2 \mu \mathrm{g} \\
3.8 \mu \mathrm{g} \\
0.4 \mu \mathrm{g} \\
2.4 \mu \mathrm{g}\end{array}$ & Not known & $30 \mu \mathrm{g}$ & Not known & - \\
\hline B9 & $\begin{array}{l}\text { Beef liver } \\
\text { Spinach } \\
\text { Broccoli } \\
\text { Asparagus }\end{array}$ & $\begin{array}{c}215 \mu \mathrm{g} \\
\mathrm{DFE} \\
131 \mu \mathrm{g} \\
\mathrm{DFE} \\
45 \mu \mathrm{g} \mathrm{DFE} \\
85 \mu \mathrm{g} \mathrm{DFE}\end{array}$ & $213 \mu \mathrm{g}$ DFE & $400 \mu \mathrm{g}$ & $1000 \mu \mathrm{g}$ & $48 \%$ \\
\hline B12 & $\begin{array}{l}\text { Salmon } \\
\text { Milk, low fat } \\
\text { Tuna, canned } \\
\text { Breakfast cereal, } \\
\text { fortified }\end{array}$ & $\begin{array}{l}4.8 \mu \mathrm{g} \\
1.2 \mu \mathrm{g} \\
2.5 \mu \mathrm{g} \\
1.5 \mu \mathrm{g}\end{array}$ & $4.3 \mu \mathrm{g}$ & $2.4 \mu \mathrm{g}$ & Not known & NSR \\
\hline $\mathrm{C}$ & $\begin{array}{l}\text { Orange juice } \\
\text { Tomato } \\
\text { Grape juice } \\
\text { Romine lettuce }\end{array}$ & $\begin{array}{l}93 \mathrm{mg} \\
17 \mathrm{mg} \\
70 \mathrm{mg} \\
28 \mathrm{mg}\end{array}$ & $74.4 \mathrm{mg}$ & $83 \mathrm{mg}$ & $2000 \mathrm{mg}$ & $10 \%$ \\
\hline
\end{tabular}

2 Source: Adapted from Drake (2017); Delaney \& Barke (2017); Harvard Medical School (2020)

3 Abbreviations: RAE, retinol activity equivalents; $D F E$, dietary folate equivalents; $R D A$, recommended dietary

4 allowance; UL, upper limit; EAS, estimated amount of supplementation; NSR, no supplementation required 